\title{
Role of the Pharmacist in Caring for Patients with HIV/AIDS: Clinical Practice Guidelines
}

\author{
Alice Tseng, Michelle Foisy, Christine A Hughes, Deborah Kelly, Shanna Chan, Natalie Dayneka, \\ Pierre Giguère, Niamh Higgins, Cara Hills-Nieminen, Jeff Kapler, Charles J L la Porte, Pam Nickel, \\ Laura Park-Wyllie, Carlo Quaia, Linda Robinson, Nancy Sheehan, Shannon Stone, Linda Sulz, and \\ Deborah Yoong, on behalf of the Canadian HIVIAIDS Pharmacists Network
}

\section{INTRODUCTION}

$\mathrm{O}$ ver the past decade, there have been numerous advances in HIV therapy, with 6 drug classes comprising 24 individual antiretroviral agents now available. For patients who are adherent with therapy and who have an undetectable viral load, HIV has become a chronic, manageable disease in an aging and genetically diverse population. The core goals of management remain maximal suppression of viral replication and promotion of immune reconstitution through combination antiretroviral therapy. Secondary goals of therapy include promoting long-term adherence, avoiding drug interactions, minimizing toxic effects, simplifying treatment regimens, decreasing drug costs, managing comorbid conditions, and preventing transmission of HIV by achieving undetectable viral load. ${ }^{1,2}$ Consequently, the pharmacist's role has evolved and expanded to help patients and other health care providers to achieve these goals. Pharmacists are recognized as established and integral members of HIV health care teams across Canada and the United States. ${ }^{3}$ Pharmacists' involvement in the care of HIVpositive patients has been associated with improved patient outcomes, including enhanced adherence, ${ }^{4}$ reduced pill burden and dosing frequency, greater increases in CD4 cell counts, higher rates of viral suppression, ${ }^{5,6}$ and decreases in medication errors. ${ }^{7.8}$

Guidelines and position statements on the role of the pharmacist in caring for patients with HIV/AIDS have been published by various national and international organizations, ${ }^{9-11}$ but there have been no updates since combination antiretroviral therapy came into use, about a dozen years ago. This paper provides current guidelines for a pharmacist's role in the many aspects of caring for patients with HIV/AIDS, including selecting and reviewing therapy, tailoring treatment for specific populations, counselling patients, monitoring response to therapy, guiding transitions of care, and undertaking scholarly and professional activities. The target audience for these guidelines includes new HIV pharmacy practitioners, pharmacists with an interest in HIV but limited experience or therapeutic knowledge in this area, and pharmacy students. This paper may also serve as a model of pharmacy practice for ambulatory care in other therapeutic areas.

A literature search was conducted using the electronic databases MEDLINE and PubMed from 2000 to March 2012. The following search terms were used: HIV, antiretrovirals, adverse drug reactions, drug interactions, adherence, pediatric, perinatal transmission, therapeutic drug monitoring, pharmacist, hepatitis B, hepatitis C, seamless care, and medication reconciliation. In addition, conference abstracts were searched for relevant studies. Updated guidelines for treatment of HIV and related conditions, landmark studies, and comprehensive review articles were selected for inclusion.

\section{GUIDELINES FOR PRACTICE}

\section{Selecting and Reviewing Therapy \\ 1.1 General Principles}

New information on investigational and licensed antiretrovirals continues to emerge rapidly, and data are often presented at conferences months or years before being published in the medical literature. International guidelines on HIV treatment are modified frequently to reflect findings from large clinical trials, cohort studies, and emerging research data. ${ }^{1,12,13}$ Pharmacists should be familiar with current treatment principles so that they can effectively manage and optimize pharmacotherapy for HIV-infected individuals. Pharmacists should also be familiar with recommendations on prophylaxis and treatment of opportunistic infections that occur in conjunction with HIV infection. ${ }^{14,15}$ Useful website resources for health care professionals are presented in Table 1 .

\subsection{Resistance to Antiretroviral Drugs}

Resistance to antiretrovirals is a major cause of treatment failure. ${ }^{16}$ It is therefore important for pharmacists to understand the mechanisms of and factors contributing to development of 
Table 1. Suggested HIV Internet Resources (URLs Current as of March 2012)

Topic and Source Internet Address

\section{General information about HIV}

CATIE (formerly known as Canadian AIDS Information Exchange)

National Center for HIVIAIDS, Viral Hepatitis, STD, and TB Prevention, US Centers for Disease Control and Prevention

National Prevention Information Network, US Centers for Disease Control and Prevention

The Body PRO (HIV resource for professionals) AIDS Education Global Information System (AEGIS) HIV InSite, University of California, San Francisco Johns Hopkins HIV Guide Medscape News, HIV/AIDS

National HIV/AIDS Clinicians' Consultation Center, University of California, San Francisco

\section{Treatment guidelines for HIV and opportunistic infections}

AIDSinfo, US Department of Health and Human Services

International Antiviral Society-USA

British HIV Association

European AIDS Clinical Society

www.catie.ca

www.cdc.gov/nchhstp/Default.htm

www.cdenpin.org/scripts/hiv/

www.thebodypro.com/ www.aegis.com

http://hivinsite.ucsf.edu/ www.hopkinsguides.com/hopkins/ub/learn\#hiv www.medscape.com/hiv www.nccc.ucsf.edu

\section{Drug resistance}

HIV Drug Resistance Database, Stanford University

HIV Drug Resistance Mutations, International Antiviral Society-USA

HIV French Resistance

HIVresistanceWeb

Understanding and interpreting antiretroviral resistance (online learning module; L. Robinson), CATIE

\section{Drug interactions}

Immunodeficiency Clinic, Toronto General Hospital

University of Liverpool HIV Pharmacology Group

Database of Antiretroviral Drug Interactions, HIV InSite,

University of California, San Francisco

Clinical Care Options HIV

HIV Medication Guide (Antony Gagnon and Rachel Therrien)

\section{Medication information sheets}

Immunodeficiency Clinic, Toronto General Hospital

CATIE (formerly known as Canadian AIDS Information Exchange)

British Columbia Centre for Excellence in HIV

Southern Alberta HIV Program

HIV Medication Guide (Antony Gagnon and Rachel Therrien) AIDSinfo Drug Database, US Department of Health and Human Services Bulletin of Experimental Treatments for AIDS (BETA)

http://aidsinfo.nih.gov/guidelines www.iasusa.org/guidelines/index.html www.bhiva.org/ClinicalGuidelines.aspx www.europeanaidsclinicalsociety.org/index.php? option=com_content\&view=article\&id=59\&Itemid=41

http://hivdb.stanford.edu/ www.iasusa.org/resistance_mutations/index.html www.hivfrenchresistance.org/ www.hivresistanceweb.com/index.shtml www.catie.ca/ELearning/eng/launchPad.html

Medication information sheets in languages other than English

\section{AIDS InfoNet}

HIV Medication Guide (Antony Gagnon and Rachel Therrien)

Multilingual HIV Treatment Information

POZ Latino

\section{Information about crushing or splitting antiretrovirals}

Immunodeficiency Clinic, Toronto General Hospital

Florida/Caribbean AIDS Education and Training Center

Institute for Safe Medication Practices (US)

National HIV/AIDS Clinicians' Consultation Center, University of California, San Francisco www.hivclinic.ca/main/drugs_interact.html www.hiv-druginteractions.org/

http://hivinsite.ucsf.edu/insite?page=ar-00-02

www.clinicaloptions.com/HIV.aspx

www.hivmedicationguide.com/

www.hivclinic.ca/main/drugs_fact.html

www.catie.ca/en/fact-sheets

www.cfenet.ubc.ca/our-work/initiatives/drug-treatmentprogram/hiv-medication-information-sheets

www.albertahealthservices.ca/

services. asp? pid=service\& rid $=1001306$

www.hivmedicationguide.com/

http://aidsinfo.nih.gov/drugs

www.sfaf.org/hiv-info/hot-topics/beta/

www.aidsinfonet.org/

www.hivmedicationguide.com/

www.treathivglobally.ca/

www.poz.com/latino/

www.hivclinic.ca/main/drugs_extra.html www.faetc.org/PDF/Pocket_Guides/

Pediatric_hiv_Drug_Card.pdf www.ismp.org/tools/donotcrush.pdf www.nccc.ucsf.edu/docs/ARV_dosage_modification table_1-2011.pdf 
Table 1. Suggested HIV Internet Resources (URLs Current as of March 2012) (Part 2 of 3)

Topic and Source Internet Address

Pregnancy and family planning in HIV

Antiretroviral Pregnancy Registry

Motherisk: HIV Treatment in Pregnancy

CATIE (formerly known as Canadian AIDS Information Exchange)

www.motherisk.org/women/index.jsp

www.catie.ca/en/practical-guides/you-can-have-healthypregnancy-if-you-are-hiv-positive

\section{Resources for persons living with HIV/AIDS}

The Body

$\mathrm{POZ}$

www.thebody.com/

www.poz.com/

POZ Latino

www.poz.com/latino/

AIDSmeds

www.aidsmeds.com/

Project Inform

www.projectinform.org

\section{Access to HIV drugs (federal and provincial programs)}

CATIE (formerly known as Canadian AIDS Information Exchange)

www.catie.ca/en/treating-hiv/access-hiv-and-hepatitis-cdrugs-federal-provincial-and-territorial-drug-access-program

Immunodeficiency Clinic, Toronto General Hospital www.hivclinic.ca/main/drugs_reimbuse.html

\section{News and research}

\section{NAM AIDSmap}

The Body PRO (HIV resource for professionals)

CATIE (formerly known as Canadian AIDS Information Exchange) amFAR (formerly known as American Foundation for AIDS Research) Harvard School of Public Health AIDS Initiative Journal of the American Medical Association, HIV/AIDS collection

\section{Information on complementary and alternative medicine}

Natural Standard

Natural Medicines Comprehensive Database

CAMline

Memorial Sloan-Kettering Cancer Center

\section{HIV conference abstracts}

HIV pharmacology workshops

- HIV and hepatitis coinfection workshops

- HIV drug resistance workshops

- Pharmacology of hepatitis therapy workshops

- HIV transmission workshop

Conference on Retroviruses and Opportunistic Infections (CROI) (1997 to present)

International AIDS Society

- Conference on HIV Pathogenesis and Treatment (2001 to present)

- International AIDS Conferences (2002 to present)

AIDS conferences website

- International Workshop on Adverse Drug Reactions and Lipodystrophy in HIV (1999 to present)

- International AIDS Conferences (1989-2004)

- International Congress on Drug Therapy in HIV Infection (1994 to present)

- British HIVIAIDS Association (BHIVA)

- European AIDS Clinical Society conferences (2001-2005)

Canadian Association for HIV Research (CAHR) conferences (2001 to present)

Interscience Conference on Antimicrobial Agents and Chemotherapy (ICAAC) www.icaac.org/
www.Hivpresentation.com

www.aidsmap.com/en/

www.thebodypro.com/

www.catie.ca/en/news

www.amfar.org

www.aids.harvard.edu/index.html

http://jama.ama-assn.org/cgi/collection/hiv_aids

www.naturalstandard.com (subscription required)

http://naturaldatabase.therapeuticresearch.com/

home.aspx?cs=\&s=ND (subscription required)

www.camline.ca/

www.mskcc.org/cancer-care/integrative-medicine/aboutherbs-botanicals-other-products

www.Retroconference.org www.iasociety.org/AbstractSearch.aspx

www.aegis.com/conferences/ 
Table 1. Suggested HIV Internet Resources (URLs Current as of March 2012) (Part 3 of 3)

Topic and Source Internet Address

\section{Continuing education and self-study}

American Academy of HIV Medicine (AAHIVM): HIV Specialist and HIV Expert certification

Clinical Care Options HIV

CMEonHIV

International Antiviral Society-USA: Cases on the Web

University of Washington HIV Web Study (case-based clinical curriculum) ViralEd

CME: HIV grand rounds, HIV InSite, University of California, San Francisco Conference on Retroviruses and Opportunistic Infections

University at Buffalo, The State University of New York, School of Pharmacy and Pharmaceutical Sciences: HIV online educational offerings (HIV Pharmacotherapy Practice-Based Program,

HIV Pharmacotherapy Community Pharmacy CE, and

HIV Pharmacotherapy Annual Update)

John Hopkins Point of Care Information Technology (POC-IT Guides) www.aahivm.org/

www.clinicaloptions.com/HIV.aspx

www.cmeonhiv.com/

www.iasusa.org/cow

http://depts.washington.edu/hivaids/index.html www.viraled.com/

http://hivinsite.ucsf.edu/insite?page $=$ cme-00-00 http://retroconference.org

https://tdm.pharm.buffalo.edu/hiv_cert_main/ drug resistance. Although drug resistance mutations can be transmitted from person to person, resistance typically arises through persistent viral replication in the presence of suboptimal antiretroviral therapy, caused by nonadherence, reduced potency, or subtherapeutic serum concentrations secondary to interactions or poor absorption. ${ }^{17,18}$ Genotypic resistance assays can be used to detect mutations in viral genes known to confer resistance to antiretroviral agents. ${ }^{1}$ Genotypic testing is recommended as the preferred form of resistance testing and should be performed before initiation of combination antiretroviral therapy and after treatment failure, to guide the selection of effective antiretroviral agents. ${ }^{16,17,19}$ Genotypic testing has been shown to be beneficial when performed at viral loads above 1000 copies $/ \mathrm{mL}$. Testing at lower viral loads (i.e., 500-1000 copies/mL) may be unsuccessful but may still be considered. Phenotypic assays measure the ability of the virus to replicate at various drug concentrations and may be useful, in combination with genotype results, for patients with extensive drug resistance mutations. ${ }^{1}$ Because drug resistance mutations wane after therapy is stopped, resistance testing should be performed while the patient is still receiving antiretrovirals or within 4 weeks of discontinuing treatment. ${ }^{17}$

Pharmacists can play an important role in preventing the development of drug resistance by ensuring selection of potent antiretroviral regimens; monitoring and reinforcing the need for strict adherence; screening for and managing drug-drug interactions; anticipating and effectively managing adverse effects, as a means to increase adherence; providing appropriate education about the relationship between nonadherence and development of resistance; and aggressively managing treatment failure by switching therapy to prevent further accumulation of resistance mutations. ${ }^{17}$ Several resources are available to assist health care providers in interpreting the results of genotypic resistance tests (Table 1).

\subsection{Management of Drug Interactions}

In addition to antiretrovirals for their HIV infection, many patients require treatment for concomitant conditions. While the need for primary or secondary prophylaxis of opportunistic infections has declined because of potent combination antiretroviral therapy, ${ }^{20}$ patients are now living longer and experiencing comorbidities such as cardiovascular disease, hyperlipidemia, hypertension, diabetes mellitus, gastrointestinal conditions, osteoporosis, renal disease, and non-AIDS-related cancers, which may be manifestations of long-term toxic effects of the antiretrovirals, increasing age, or the virus itself. ${ }^{21}$ Furthermore, treatment may be required for other indications, including hepatitis coinfection, psychiatric illness, illicit substance use, or solid-organ transplantation. Finally, patients may also be taking vitamins, food supplements, complementary or alternative medicine (CAM) agents, or recreational agents, either regularly or occasionally. Therefore, there is a high potential for drug interactions in this population. Clinically significant drug interactions have been reported in $27 \%-40 \%$ of HIV patients receiving combination antiretroviral therapy, with use of protease inhibitors, use of non-nucleoside reverse transcriptase inhibitors (NNRTIs), number of concomitant medications, current use of illicit drugs, coinfection with hepatitis $\mathrm{C}$ virus ( $\mathrm{HCV}$ ), and age identified as independent risk factors. ${ }^{22-25}$

Pharmacists should be aware of the types and mechanisms of drug interactions if they are to manage such interactions effectively. Pharmacokinetic interactions involving drug metabolism are becoming increasingly complex, because many antiretrovirals (notably the protease inhibitors and NNRTIs) are both substrates for and inhibitors or inducers of cytochrome P450 hepatic enzymes and drug transporters. The C-C chemokine receptor type 5 (CCR5) inhibitor maraviroc is also 
a substrate of isozyme CYP3A4 and is susceptible to interactions with other inducers or inhibitors, although it does not exert any inducing or inhibiting effects on its own. Pharmacokinetic interactions result in altered concentrations of one or more of the interacting drugs. A beneficial example is the use of lowdose ritonavir to boost the concentrations of protease inhibitors or other drugs, which allows lower or less frequent dosing. ${ }^{26}$ However, pharmacokinetic interactions may result in subtherapeutic drug concentrations, which could lead either to viral breakthrough (and hence development of resistance or suboptimal management of disease or symptoms) or to supratherapeutic levels (resulting in toxic effects and possibly nonadherence and/or increased morbidity). ${ }^{23}$ Of note, the integrase inhibitor raltegravir is not a cytochrome P450 substrate, inducer, or inhibitor and thus may be suitable for inclusion in a patient's regimen when trying to minimize interactions with other drug classes. ${ }^{27,28}$ However, raltegravir is affected by glucuronidation, and higher doses are required in the presence of rifampin. ${ }^{29}$ Preliminary data suggest that raltegravir may be affected by P-glycoprotein, although clinically significant interactions via this mechanism have not been well defined..$^{30} \mathrm{In}$ contrast, the investigational integrase inhibitor elvitegravir, which is in late-stage development, is a CYP3A4 substrate and requires boosting with an inhibitor to achieve therapeutic concentrations. ${ }^{31}$

Pharmacodynamic interactions may affect the efficacy or toxicity of a drug in an additive, synergistic, or antagonistic manner. An example of an undesirable HIV-related pharmacodynamic drug-drug interaction occurs with the combination of didanosine and tenofovir. Despite virologic suppression, paradoxical decreases in CD4 cell counts ${ }^{32,33}$ and increased toxic effects of didanosine have been observed with this combination,$^{34}$ and coadministration of these 2 drugs should therefore be avoided.

Interactions between antiretrovirals and other drug classes have not been exhaustively elucidated, so pharmacists need to be aware of the pharmacological and pharmacokinetic characteristics of specific agents to identify or predict potential drug interactions. ${ }^{35}$ The field of HIV-related drug interactions is growing rapidly, making many of the standard drug information resources out of date. Therefore, pharmacists must utilize current sources of information to make an accurate assessment. Top-ranked HIV drug interaction websites have been identified through independent evaluations based on specific criteria, including content, reliability, accessibility, and ease of navigation $^{36,37}$ (see Table 1). In situations of suspected or potential drug interactions, close clinical, virological, and therapeutic drug monitoring is warranted. In some instances, dose adjustments may be beneficial in optimizing the clinical response, including viral suppression..$^{38}$ Other management options include altering dosing frequency or replacing one agent with another drug that has lower potential for interaction.

\subsection{Complementary or Alternative Medicine}

The concomitant use of CAM with antiretrovirals is common, with up to $60 \%$ of HIV-infected individuals reporting the use of such therapies in a recent survey. ${ }^{39}$ This rate may underestimate the true frequency, as many CAM users are reluctant to divulge use of these agents to their treating physicians..$^{40} \mathrm{HIV}$-infected patients may turn to these forms of therapy to manage symptoms associated with HIV or its treatment such as fatigue or neuropathy, to exert control over their own health care, or to satisfy cultural or religious beliefs. ${ }^{39}$

Many concerns may be associated with broad and unreported use of CAM, including safety concerns and risk of potential drug interactions. Some herbal products, such as $\mathrm{St}$ John's wort, echinacea, garlic, and Gingko biloba, have been shown to induce or inhibit important metabolic pathways involved in the metabolism of protease inhibitors and NNRTIs, including CYP450, uridine 5'-diphospho-glucuronosyltransferase (UGT), and P-glycoprotein pathways. ${ }^{41}$ In one case, an HIV-positive man experienced a $68 \%$ reduction in efavirenz concentrations, which caused viral breakthrough and drug resistance, following initiation of Gingko biloba, a known inducer of isozyme CYP3A. ${ }^{42}$ In another case, elevated plasma concentrations of lopinavir and severe diarrhea were noted with concomitant use of efamol (a component of evening primose oil that has been shown to inhibit isozymes CYP3A4 and CYP2D6 in vitro). ${ }^{43}$ Unfortunately, comprehensive information about potential pharmacokinetic interactions between antiretrovirals and CAM agents is scarce. Antiretroviral dosing, viral sensitivity, and adherence also play determining roles in the overall clinical outcome. As a result, the decision as to whether or not CAM is safe for use with combination antiretroviral therapy is complex and based mostly on extrapolation. Online resources about CAM are listed in Table 1.

In some studies, CAM was associated with nonadherence with combination antiretroviral therapy, ${ }^{40}$ and CAM users may have a less favourable attitude toward traditional medicine than other patients..$^{40}$ In addition, consumers may have the misconception that CAM products are harmless because they are "natural". However, numerous adverse effects, including dermatological, gastrointestinal, hematological, hepatotoxic, and central nervous system effects, have been reported in association with CAM use by HIV-infected patients. ${ }^{44,45}$ A US consumer organization recently identified 12 of the most dangerous ingredients currently found in dietary supplements $^{46}$ : aconite, bitter orange, chaparral, colloidal silver, coltsfoot, comfrey, country mallow, germanium, greater celandine, kava, lobelia, and yohimbe. These products have been associated with numerous health hazards, including cancer, heart problems, and death, and should be avoided.

Finally, patients need to be reminded that, in contrast to conventional medications, the large majority of CAM products are not licensed and are not required to meet the standards for efficacy, safety, bioavailability, and stability that are required for 
conventional medications before they can be marketed. In the United States, all food additives and drugs must be approved by the Food and Drug Administration. However, herbal remedies are classified as dietary supplements, and manufacturers do not have to prove the safety and effectiveness of dietary supplements before marketing them. In Canada, the Natural Health Product Regulations require licensure for vitamins and minerals, herbal remedies, homeopathic and traditional (e.g., Chinese or Ayurvedic) medicines, and supplements. To receive either a Natural Product Number (NPN) or a Homeopathic Medicine Number (DIN-HM), the manufacturer must meet specific labelling and packaging requirements, must follow good manufacturing practices, and must provide proper evidence of safety and efficacy (for information, see Health Canada's website concerning regulation of natural health products in Canada: www.hc-sc.gc.ca/dhp-mps/prodnatur/about-apropos/indexeng.php\#gmp\#gmp). Pharmacists may choose to recommend products with an NPN or DIN-HM over those that do not.

Pharmacists can play a crucial role by providing reliable information about CAM to help patients understand the potential risks, benefits, and uncertainties regarding specific products of interest. When indicated, potential interventions include offering therapeutic alternatives, evaluating the risk of drug interactions, recommending therapeutic drug monitoring, and ensuring optimal adherence with combination antiretroviral therapy. ${ }^{47}$

\subsection{General Promotion and Maintenance of Health}

With the evolution of HIV infection into a chronic, manageable disease, patients who are receiving stable combination antiretroviral therapy may be seen less frequently. The emphasis has therefore shifted to issues of routine primary care, with attention on promotion and maintenance of health. ${ }^{48}$ Pharmacists, especially those practising in ambulatory or community settings, can play a significant role in this aspect of care. They can help to ensure that patients are up to date on routine vaccinations and immunizations, advise on proper diet and nutrition, and provide counselling on personal health and safety issues such as sun protection, routine oral hygiene, safer sex practices, management of erectile dysfunction, prevention of falls, and smoking cessation.

\section{Tailoring Therapy for Specific Populations}

\subsection{Women}

Women and families living with HIV pose unique challenges for pharmacists. The HIV-infected woman who may be caring for her infected partner and/or children often requires additional support from all members of the health care team. The incidence of adverse effects of antiretrovirals may be greater among women than among men. These adverse effects include nevirapine-induced hepatotoxicity and lactic acidosis, and distinctive metabolic complications. ${ }^{1}$ These factors should be carefully considered and discussed with women to ensure selection of the most appropriate combination antiretroviral regimen. As the life expectancy of HIV-infected individuals improves, issues of fertility and risk reduction when planning pregnancy will become more common. For women of childbearing age, choosing a regimen that is safe during pregnancy is of paramount importance. In particular, efavirenz is categorized as a class $\mathrm{D}$ agent and should be avoided unless effective and consistent contraception is being used. Conversely, pharmacists should also be comfortable discussing methods of contraception and need to be aware of drug interactions with hormonal contraceptives. ${ }^{1,49}$

All pregnant women, regardless of their viral load or CD4 cell count, should be offered treatment with combination antiretrovirals to prevent vertical transmission of HIV ${ }^{1,50}$ Known or potential effects of HIV infection or medications on the fetus are significant issues, and referral to health care providers with expertise in perinatal HIV care is crucial. Physiologic changes induced by pregnancy may also affect plasma concentrations of antiretrovirals, and therapeutic drug monitoring with dosage adjustment may need to be considered. Health care providers can obtain information on the safety of specific antiretrovirals in pregnancy by reviewing current guidelines $^{50}$ or by contacting Motherisk (a Canadian program for women and health care professionals, based at The Hospital for Sick Children and focusing on medication safety in pregnancy) $)^{51}$ (see Table 1). Health care providers can also register their pregnant patients who are taking antiretrovirals with the US Antiretroviral Pregnancy Registry (see Table 1 for website information).

\subsection{Pediatric Patients}

In utero, intrapartum, and potentially postpartum exposure of a neonate born to an HIV-positive mother places the neonate at risk of perinatally acquired HIV. ${ }^{50,52}$ The use of combination antiretroviral therapy during these critical stages of transmission has lowered the transmission rate to less than $2 \%$ in the developed world. ${ }^{52}$ Because maternal antibodies to HIV may persist in the newborn for up to 18 months, diagnosis of perinatally acquired HIV infection relies on virologic assays that directly detect HIV. Assessment of HIV-positive infants must take into account age-specific differences in CD4 cell counts. $^{52}$

Drug disposition differs between children and adults because of pediatric physiology and the maturation continuum of the developing body, specifically the organs involved in metabolism and clearance of drugs. ${ }^{53}$ These pharmacokinetic differences between adults and children have been studied for some antiretrovirals, such as lopinavir, ${ }^{54,55}$ but such study is often lacking for newer agents. ${ }^{52}$ Genetic differences in age-related phenotypic alterations of hepatic enzyme activity may partially contribute to the differences in pediatric clearance 
of many drugs. ${ }^{56}$ Significant inter- and intra-patient variability of antiretroviral levels in children has been demonstrated, which supports the role of therapeutic drug monitoring in individualizing dosing calculations for pediatric patients. ${ }^{57}$ There is a role for pharmacists in accurate calculation of pediatric doses of antiretrovirals (i.e., based on weight, body surface area, and/or age). Therefore, these patient characteristics should be confirmed at each visit to ensure appropriate adjustment of antiretroviral doses as children grow. Unfortunately, extensive scientific and clinical research in pediatric patients, including HIV-related research, is lacking. Legislative initiatives are now stimulating pediatric research on drug clearance and dose optimization. ${ }^{58}$ Nonetheless, pediatric pharmacists must continue to lobby to have pediatric dosing guidelines and formulations made available when new antiretrovirals are marketed for the adult population.

One of the main concerns in providing pediatric care is the issue of palatability of medications and the impact of this factor on adherence and treatment success. Antiretrovirals are usually marketed with no accompanying oral liquid formulation or stability guidelines to direct splitting or crushing of tablets. Furthermore, even when liquid formulations are available, some products pose toxicity risks for very young infants. For example, the oral solution of lopinavir-ritonavir contains alcohol and propylene glycol, and preterm neonates may be at increased risk of adverse events through a limited ability to metabolize propylene glycol..$^{59}$ Several useful resources on formulation options are available to assist clinicians in optimizing delivery of antiretrovirals in the pediatric population. ${ }^{60}$

The challenge of strict adherence to combination antiretroviral therapy plagues patients of all ages and is magnified in the adolescent age group. ${ }^{61}$ Patients in this age group who have taken combination therapy since early childhood may experience "regimen fatigue" and may have high rates of virologic resistance and other consequences of extended exposure to antiretrovirals. Normal developmental transitions of adolescence, such as rebellion and the need for autonomy, a focus on peer relationships, and inattention to future consequences, can adversely affect adherence with medication regimens. Additional challenges include sexual debut (with accompanying concerns related to partner disclosure, pregnancy, and transmission risk) and psychiatric or neurocognitive morbidity possibly related to the long-term effects of HIV infection, exposure to antiretrovirals, and/or environmental stressors, including family disruption, economic hardship, marginalization, and discrimination. ${ }^{62}$ Potential interventional strategies continue to be explored in the struggle to assist adolescent patients in improving their adherence. ${ }^{63}$

For younger infants and children, it is important to consider additional factors such as adherence and the abilities of the caregivers who will be administering the medication, the caregiver's lifestyle and schedule, the complexity of the drug regimen, and confidentiality issues related to sharing the HIV diagnosis with members of the extended family and friends. Directions on how to manage refused doses or partially ingested doses (due to spitting up of doses) should also be discussed with the caregiver.

A complicating factor for adherence within this subpopulation is the uniquely pediatric concept that some patients may not know their own diagnosis of HIV infection. Disclosure is typically a gradual process, initiated when the child is very young and expanded over time until the patient's parent or caregiver feels that the child is sufficiently mature to understand the significance of the diagnosis. ${ }^{64}$ In particular, lack of knowledge of the diagnosis may prevent children from understanding the importance of adherence. However, to prevent disclosure of diagnoses to people outside the family through identification of medications, practical dosing schedules need to be designed that avoid administration of antiretrovirals during daycare or school hours.

Transitioning from pediatric to adult care is an important issue that needs to be planned in advance to minimize anxiety and avoid unintentional gaps in medical care and/or antiretroviral treatment. Adolescents with chronic disease face many challenges in moving from a child-centred, interdisciplinary, "one-stop shopping" model of care to an adult care model in which increased personal responsibility is expected, and medical and psychosocial services may be fragmented. Adolescents living with HIV also face unique psychosocial and medical needs that make transition planning much more complicated than is the case for other chronic illnesses. These needs may relate to stigma and the requirement for disclosure to sexual partners, friends, and/or service providers, as well as loss of the "family" of pediatric and adolescent care team members. In addition, adolescents and young adults may be less likely to have medical or drug insurance than people in other age groups, which can significantly impair their access to care..$^{65}$

\subsection{Patients with Comorbidities}

The success of combination antiretroviral therapy, yielding high rates of viral suppression and immune recovery, means that patients with HIV are living longer, and the population as a whole is aging. In addition, older people are becoming newly infected with HIV. Comorbidities are common among HIVinfected patients, with consumption of alcohol, use of tobacco products and illicit substances, low body mass index, low socioeconomic status, and coinfection with HCV being some of the contributing factors. The prevalences of depression, liver and renal disease, and multimorbidity are also higher among HIV-infected patients. ${ }^{66}$ Traditional comorbidities of elderly patients occur at an earlier age in HIV-infected individuals. These patients are at increased risk of premature cardiovascular disease, neurocognitive disease, bone disease (including osteopenia and fractures), and non-AIDS cancers, perhaps because of ongoing viral inflammation that is not normalized even with combination antiretroviral therapy. ${ }^{67}$ Starting 
antiretroviral medications when CD4 cell counts are less than $500 \mathrm{cells} / \mu \mathrm{L}$ (rather than when counts are greater than 500 cells $/ \mu \mathrm{L}$ ) has been shown to increase the risk of death from non-AIDS-related causes. ${ }^{66}$

The incidence of cardiovascular disease and diabetes is increased among HIV-positive individuals. ${ }^{66}$ Patients with HIV infection have lower levels of high-density lipoprotein cholesterol and higher levels of low-density lipoprotein cholesterol than uninfected patients, and the prevalence of smoking is higher among HIV-infected patients. ${ }^{67}$ Antiretroviral drugs have been associated with metabolic adverse effects, such as hyperlipidemia, insulin resistance, and/or lipodystrophy, which may result in premature development of cardiovascular disease, ${ }^{68}$ and certain antiretrovirals may be associated with an increased risk of myocardial infarction. ${ }^{1}$ Patients should be screened with tools such as the Framingham cardiovascular risk score (see www.framinghamheartstudy.org/risk/coronary.html). Modifiable risk factors such as dyslipidemia, diabetes, and hypertension should be identified and managed according to guidelines for non-HIV-infected patients, with attention to potential interactions with antiretroviral agents. ${ }^{69-71}$ The involvement of pharmacists in smoking cessation programs and blood glucose monitoring programs can contribute to overall health promotion.

Studies have shown that HIV-infected patients have an increased risk of osteopenia and osteoporosis. The contributing role of combination antiretroviral therapy is unclear, although the long-term use of tenofovir is being investigated as a potential risk factor. ${ }^{72}$ Pharmacists should assess the need for calcium and vitamin D supplementation and should screen for other risk factors for osteoporosis, including smoking, alcohol use, low body mass index, and medications such as anticonvulsants and corticosteroids. Levels of vitamin D have been found to be low in HIV patients, with the majority qualifying for supplementation. ${ }^{73}$ Although routine population screening for vitamin $\mathrm{D}$ deficiency is not recommended, screening may be appropriate for HIV-positive patients older than 50 years and/or patients with a history of fractures, osteoporosis, or falls. For patients with vitamin D deficiency, a number of options for replacement therapy are recommended. ${ }^{74.76}$ Updated guidelines from the Endocrine Society recommend 50000 IU of vitamin $\mathrm{D}_{2}$ or $\mathrm{D}_{3}$ per week (or 6000 IU of vitamin $\mathrm{D}_{2}$ or $\mathrm{D}_{3}$ daily) for 8 weeks, followed by 1500 to 2000 IU per day as maintenance therapy. ${ }^{76}$

In addition to its recommendations for treating vitamin $\mathrm{D}$ deficiency, the Endocrine Society has guidelines for preventing deficiency. For prevention in the general population, the Society recommends daily vitamin $\mathrm{D}$ supplementation of at least $600 \mathrm{IU}$ in HIV-negative adults 19-50 years of age and doses of 600-800 IU for adults between 50 and 70 years of age, with ideal intake possibly being as high as 1500-2000 IU daily. For adults who are obese (body mass index $>30 \mathrm{~kg} / \mathrm{m}^{2}$ ) and for those who are taking anticonvulsants, glucocorticoids, and/or antiretrovirals that may increase vitamin D catabolism (such as regimens containing efavirenz), ${ }^{77}$ the Endocrine Society panel recommends that doses 2- to 3 -fold higher may be required. ${ }^{76}$ Patients should be encouraged to consume adequate vitamin D and calcium (1000-1200 mg daily for adults ${ }^{78}$ ) through their diet. Patients should also be counselled to engage in regular weight-bearing exercise, to minimize alcohol and tobacco use, and to avoid or prevent falls. Screening of bone mineral density by dual-energy $\mathrm{x}$-ray absorptiometry should be considered for HIV-infected patients over the age of 50, especially those with at least one other risk factor. Osteoporosis can be treated with bisphosphonates, similar to therapy for HIVnegative patients. ${ }^{79}$

Given the higher incidence of renal and liver disease in the HIV-infected population, along with the risk of hepatotoxicity and nephrotoxicity associated with antiretrovirals, dosing medications appropriately for renal and hepatic function is important. As patients age, absorption and clearance of antiretrovirals may change, which can lead to irregular drug levels. Patients should undergo regular laboratory monitoring for toxicity and efficacy. The pharmacist can play a role in monitoring use of over-the-counter medications that can contribute to hepatotoxicity and nephrotoxicity, such as acetaminophen and nonsteroidal anti-inflammatory drugs.

HIV-associated neurocognitive disorders are more common in patients with a low CD4 cell count but may persist despite combination antiretroviral therapy. ${ }^{80}$ There is some concern that certain antiretrovirals do not penetrate the central nervous system (CNS), possibly leading to continued viral replication in the cerebrospinal fluid. A ranking of antiretrovirals by their CNS penetration-effectiveness score has been validated, ${ }^{80}$ and some clinicians try to select regimens that are more "neuroactive". However, use of better CNS-penetrating antiretrovirals to improve neurocognitive performance and prognosis has not been well established, and research in this area is ongoing. Pharmacists need to be aware of the potential for declining cognition in this population and should tailor patient information and monitor for adherence accordingly.

\subsection{Patients with Coinfection with Hepatitis Virus}

Hepatitis B virus (HBV) and HCV share common routes of transmission with HIV, and coinfection is frequent. Management of patients with such coinfections may involve multiple agents having possible interactions and significant adverse effects. The order in which to treat concurrent conditions depends on the risk of progression of liver disease, the CD4 cell count, and the need for combination antiretroviral therapy. Furthermore, the selection of antiretrovirals is influenced by the need to treat HBV or HCV infection. Guidelines have been developed for when to initiate treatment in HIV-positive patients who have HBV or HCV coinfection, what medications to use, and monitoring parameters. ${ }^{1.81,82}$ 
Vaccinations to prevent further liver infections and complications are recommended for all HIV-positive patients coinfected with either HBV or HCV. More specifically, all coinfected patients should receive hepatitis A vaccine if they are determined to be non-immune to hepatitis $\mathrm{A}$. If the patient is coinfected with HCV and non-immune to HBV, then HBV vaccine should also be given. All coinfected patients should be advised to abstain from drinking alcohol; appropriate referrals can be made if alcohol dependency is a problem.

\subsubsection{Hepatitis $B$}

Tenofovir, lamivudine, and emtricitabine are active against both HIV and HBV, and the anti-HBV drug entecavir also has weak anti-HIV activity. ${ }^{83,84}$ Therefore, treatment choices for patients coinfected with HIV and HBV need to be made carefully to avoid inadvertent monotherapy for either infection and the possible development of HBV and/or HIV drug resistance.

In general, $\mathrm{HBV}$ is treated with a combination of 2 antivirals, whereas standard combination antiretroviral therapy consists of 2 nucleosides plus a third agent. Therefore, when treating a patient coinfected with HIV and HBV, tenofovir plus emtricitabine or lamivudine should be used as the nucleoside backbone of a fully suppressive combination regimen. If tenofovir cannot be used, then an alternative antiretroviral should be selected, and entecavir should be added for additional anti-HBV activity. ${ }^{1}$ If HIV therapy needs to be modified because of virologic failure or HIV drug resistance, the antiretrovirals active against HBV should be continued to maintain adequate $\mathrm{HBV}$ suppression and to prevent relapse or worsening of the HBV infection. A new, fully suppressive combination antiretroviral regimen should be selected for treatment of the HIV infection.

\subsubsection{Hepatitis C}

The optimal time to treat HCV in an HIV-positive patient has not been determined. However, it is recognized that HCV coinfection is associated with an increased risk of liver cirrhosis and hepatocellular carcinoma and higher rates of antiretroviralinduced hepatotoxicity relative to patients with HIV infection alone. In patients with acute HCV infection and a CD4 cell count higher than 350 cells $/ \mathrm{mm}^{3}$, HCV therapy can be commenced before combination antiretroviral therapy, as rates of sustained virological response are significantly decreased if anti$\mathrm{HCV}$ therapy is delayed for more than a year after the onset of acute infection. ${ }^{82}$ However, if the patient's $\mathrm{CD} 4$ cell count is less than 350 cells $/ \mathrm{mm}^{3}$, most experts would recommend treating the HIV infection first (to improve the $\mathrm{CD} 4$ cell count) before starting HCV therapy, as the latter may further decrease CD4 cell levels. ${ }^{13}$

Pharmacists should be aware of key drug interactions if simultaneous treatment of $\mathrm{HCV}$ and HIV infection is required.
For example, didanosine, stavudine, and zidovudine should be avoided with pegylated interferon and ribavirin because of increased risks of mitochondrial toxicity and anemia. ${ }^{81,85}$ Some controversy exists as to whether concomitant abacavir may be associated with a reduced response to pegylated interferon and ribavirin, ${ }^{86-88}$ but a recent in vitro study showed that the antiHCV activity of ribavirin was not modified by abacavir. ${ }^{89}$ It is important to achieve adequate ribavirin trough levels via weight-based dosing, ${ }^{85,90}$ and there is insufficient evidence to recommend avoiding this combination.

Two recently approved direct-acting antivirals for HCV infection, boceprevir and telaprevir, are substrates and inhibitors of isozyme CYP3A4 and P-glycoprotein. Thus, the possibility for interactions exists between these agents and protease inhibitors, NNRTIs, and maraviroc. ${ }^{91}$ Negative 2-way interactions have been observed between both boceprevir and telaprevir and ritonavir-boosted protease inhibitors, with significant reductions in exposure to HCV agents and HIV protease inhibitors. Therefore, telaprevir should not be coadministered with ritonavir-boosted darunavir, fosamprenavir, or lopinavir, ${ }^{92}$ and boceprevir is not recommended for use with any boosted protease inhibitor. ${ }^{93}$ Concentrations of boceprevir are significantly reduced in the presence of efavirenz, and this combination should be avoided. ${ }^{94}$ Similarly, telaprevir concentrations are reduced by concomitant efavirenz; the possibility of using higher telaprevir doses to overcome this interaction is being explored. ${ }^{95}$ In contrast, raltegravir may be used with both HCV agents without dosage adjustment. ${ }^{96,97}$

Both antiretrovirals and current HCV treatment have multiple adverse effects. For instance, pegylated interferon and ribavirin have toxic effects that overlap with those of zidovudine and efavirenz, resulting in additive anemia and CNS effects, including depression, mood changes, and suicidality. Ribavirin may cause a decrease in the total lymphocyte count, which can affect CD4 cell counts. Therefore, the CD4 percentage, rather than the absolute number, may be a more appropriate measure of immunologic efficacy during ribavirin treatment. Hepatotoxicity may occur more frequently in patients with coinfection. Close monitoring is required, and dosage adjustments or alterations of combination antiretroviral therapy may be required if hepatic decompensation occurs.

These interactions illustrate the complexity of treating HIV and HCV coinfection. Further research is needed in this area to identify optimal combinations of agents in patients with coinfection. Pharmacists have a key role in ensuring the safety of therapy and assisting with adherence challenges to optimize treatment response to both HIV and HCV therapies and to maintain overall quality of life for patients during the course of HCV treatment and beyond. 


\subsection{Marginalized Patient Groups}

Marginalized members of society, such as people who use various substances, people who are homeless, and those with psychiatric disorders, may have additional needs.

Patients with HIV infection should be encouraged to provide a comprehensive list of any recreational drugs that they use routinely or occasionally. The importance of this disclosure must be explained to the patient. Pharmacists need to screen for potentially harmful drug interactions between antiretrovirals and recreational drugs such as ecstasy (3,4-methylenedioxy- $N$ methylamphetamine or MDMA), $\gamma$-hydroxy-butyrate (also known as GHB), phencyclidine (also known as PCP), and ketamine. Many of these agents undergo metabolism in part via the CYP450 system, and adverse interactions, including death, have been reported..$^{98}$ In addition, the frequency, route, and type of recreational drugs used may affect adherence with HIV therapy. However, the ongoing use of recreational drugs should not preclude a patient from receiving appropriate combination antiretroviral therapy ${ }^{99}$ Studies have shown that, with various support programs, therapeutic success with combination therapy can be achieved, despite ongoing use of illicit drugs.99,100

Pharmacists should support patients seeking methadone maintenance therapy and/or needle exchange programs. Methadone maintenance services have yielded positive outcomes, including improved adherence and virological suppression. ${ }^{99,101}$ Since methadone is a substrate of the CYP450 hepatic enzyme system, there may be clinically relevant interactions between combination antiretroviral therapy and methadone, which may in turn lead to decreased exposure to methadone and symptoms of withdrawal. ${ }^{98}$ Pharmacists should counsel both patients and methadone prescribers about such potential interactions and the possible need for increased maintenance doses of methadone. The use of certain recreational drugs is also associated with high-risk sexual behaviour, and patients using these drugs may need referral for further counselling. ${ }^{.}$Finally, the high incidence of coinfection with HCV among injection drug users should also be considered, and special attention should be given to evaluating hepatic function in these patients, as discussed earlier.

Many patients do not have access to refrigeration, areas for safe storage of medications, regular means of transportation to appointments, telephones for follow-up, or stable housing. Therefore, whenever possible, combination antiretroviral regimens should be kept simple. Medications should be provided in small quantities at an easily accessible location, and treatment may include the use of directly observed therapy programs or coordination of administration of antiretrovirals with methadone pick-up. Directly observed therapy may be simplified by favouring once-daily combination regimens. Adherence aids to help with storage and organization of doses should be readily available at no or minimal cost, and frequent monitoring should be planned to identify and manage any obstacles to success that may arise. Pharmacists may consider enlisting the help of patient advocates or community caregivers to maintain continuity of availability and administration of medications. Counselling sessions should be concise and should take into consideration the educational and cultural background of each patient.

Depression is underdiagnosed among patients with HIV, although its estimated prevalence is believed to be as high as $42 \% .{ }^{102}$ Patients with depressive symptoms or severe anxiety may lack the motivation and self-efficacy required to attend clinic appointments or to be adherent to antiretroviral therapy. ${ }^{103}$ Untreated depression has been linked with poor health outcomes, including reduced immunologic response and death; ${ }^{104}$ efforts should therefore be made to screen patients for mental illness and institute appropriate treatment. Guidelines recommend treatment in conjunction with adherence counselling to improve depressive symptoms, adherence to antiretroviral therapy, and health outcomes. ${ }^{104}$ HIV-infected patients respond similarly to antidepressants as do uninfected patients, so selection of therapy should be based on a consideration of factors such as comorbidities, the potential for drug interactions (especially with antiretroviral therapy), and adverse effects. ${ }^{102}$ Suicidality may be also be present, so avoidance of antidepressants that may be lethal in overdose, such as tricyclic antidepressants, may be prudent.

\subsection{Immigrant and Indigent Populations}

HIV-infected patients from endemic countries present distinctive challenges to the HIV pharmacist. These patients may struggle with HIV-related stigma in a context where certain risk factors for HIV acquisition may be associated with persecution; as such, they may be reluctant to disclose their condition to friends or family and may therefore experience social isolation. They may have different beliefs about HIV treatment or financial difficulty in paying for medications, they may present with opportunistic coinfections endemic to their home countries, they may have difficulty accessing services, and/or they may suffer from post-traumatic stress disorders related to horrific events or conditions experienced before their move to a new country. ${ }^{105}$ Pharmacists need to be sensitive to these issues when discussing and managing HIV therapy. Being able to communicate with patients in their native language may reduce some barriers. The use of reliable, trustworthy, medically knowledgeable interpreters is imperative to ensure that patients adequately understand their complex medication regimens. Many cities have medical clinics that specialize in caring for immigrant populations and can help patients to get in touch with needed services. Pharmacists should try to familiarize themselves with these organizations so that they are ready to refer clients when the need arises.

Even within Canada and the United States, First Nations, Inuit, Métis, and Native American peoples face important barriers to treatment, including decreased adherence and virologic response (relative to other populations), difficulty 
accessing medications, lack of access to HIV-trained physicians and allied health care professionals, a high pregnancy rate, illicit substance use, poverty, homelessness, mental health issues, and coinfection with HCV and tuberculosis. ${ }^{106-109}$ Pharmacists should try to understand these particular needs in order to ensure that these patients have the best opportunity to realize the benefits of combination antiretroviral therapy.

\section{Patient Counselling}

\subsection{Counselling and Patient Education}

HIV disease crosses many boundaries related to sex, age, race, culture, socioeconomic status, language, and lifestyle choice. Pharmacists need to be aware of these issues and take into account the communication style and literacy level of each patient when they are providing counselling. The ultimate goal is to develop a more personal and trusting relationship, so that the patient feels comfortable and cared for and is willing to discuss any and all issues regarding his or her diseases and treatment in a confidential, nonjudgmental, nonpunitive relationship with the pharmacist.

Interviews should be conducted in a private setting. The presence of family members, partners, or friends during the counselling session can be helpful for reinforcement and ongoing patient support.

Counselling should cover practical matters related to medications. For example, some antiretrovirals are typically stored in the fridge but may be stable for several days or weeks at room temperature. Giving the patient this information will help to ensure that medications are stored properly but allows some flexibility if the patient is filling his or her own dosettes or is away from home without access to refrigeration. Also, it is important to advise the patient whether medications should be taken with or without food, and whether the type of food ingested will affect absorption of the medication. For example, fatty foods should be avoided in conjunction with administration of efavirenz, to minimize CNS toxicity. With regard to timing, all antiretrovirals administered once daily should be taken together, at the same time each day, whereas twice-daily antiretrovirals should be given approximately 10-12 hours apart, to provide consistent drug concentrations. It should also be emphasized that ritonavir must be taken at the same time as the concomitant protease inhibitor or other boosted antiretroviral, to ensure that optimal concentrations are achieved. Discussions about the adverse effects of medications should be presented in a balanced manner, with emphasis on the benefits of therapy and presentation of strategies for managing nuisance adverse effects. Patients will benefit from counselling about proactive strategies to be used if doses are missed, to minimize the risk of resistance. Providing written information at a grade 8 literacy level can help with retention of information; in some circumstances, an interpreter and/or handouts in other languages may be necessary.
The pharmacist can also be a referral source for other support and educational tools that may be of interest and use to the patient, such as websites with drug information or other patient-related information and community support groups. From counselling on vitamins, CAM, and safer sex practices, to thorough education regarding combination antiretroviral therapy and lifestyle changes required to manage the comorbidities of HIV infection, treatment, or aging, pharmacists may be the HIV health care providers who can pull everything together and communicate the information simply and efficiently in each patient counselling session.

\subsection{Adherence Issues}

Medication adherence is a crucial factor affecting the extent and duration of response to combination antiretroviral therapy. ${ }^{1}$ Suboptimal adherence to both HIV therapy and prophylactic regimens against opportunistic infection may have lasting consequences for the HIV-positive patient, including increased viral load, development of resistance, reduced efficacy of future combination therapy, increased risk of hospital admission, increased progression to AIDS, and decreased survival. ${ }^{1,110-112}$ In particular, there is a highly significant correlation between suboptimal adherence and risk of virologic failure, as well as better outcomes with adherence rates over $95 \% .{ }^{113}$ Newer combination regimens typically consist of coformulated pills of agents with longer half-lives than earlier drugs, which have been shown to be more "forgiving" of imperfect adherence. ${ }^{114,115}$ In addition to Atripla, a fixed-dose combination tablet of efavirenz, emtricitabine, and tenofovir, a second fixed-dose tablet, Complera, consisting of rilpivirine, emtricitabine, and tenofovir, has recently been licensed in both Canada and the United States. Use of single-tablet, once-daily regimens has been associated with higher adherence rates and reduced risk of hospital admission relative to multitablet, once-daily regimens. ${ }^{116,117}$ Recently published guidelines from an international panel of physicians in AIDS care recommended the use of fixed-dose combinations among regimens of equal efficacy and safety, to decrease the pill burden and enhance adherence. ${ }^{104}$

The goal remains maximal adherence, and pharmacists are uniquely positioned to help patients achieve this goal. A number of factors may complicate a patient's ability to take their combination antiretroviral therapy "as prescribed". In particular, adherence fatigue, which is relatively common, may compromise the long-term effectiveness of therapy. ${ }^{118}$ Although newer regimens generally require less frequent dosing than older regimens, adherence may still be affected by food restrictions, adverse effects, numerous drug interactions, and cost.

One of the most significant predictors of nonadherence with combination antiretroviral therapy is poor treatment competency, defined as the patient having incorrect beliefs about his or her medications and his or her disease, as well as lower optimism regarding treatment efficacy. ${ }^{119}$ A trusting, collaborative relationship between the patient and his or her 
caregivers is essential to support adherence with therapy over the long term. ${ }^{119}$ Pharmacists can play an important role in assessing readiness to begin combination antiretroviral therapy, providing education about the medications and expectations of treatment, helping patients tailor drug regimens to their lifestyle, and managing adverse effects. In a recent retrospective study, recommendations on changes to the antiretroviral regimen made by a clinical HIV pharmacist led to significant reductions in daily pill burden and dosing frequency and significant improvements in medication adherence, CD4 response, and viral suppression. ${ }^{5}$ Of critical importance is the need to ensure an uninterrupted supply of medication and assistance with financial barriers to adherence. Concerns about privacy and confidentiality should also be addressed, particularly in the community pharmacy setting.

Adherence to combination antiretroviral therapy can be reasonably assessed through regular review of refill frequency ${ }^{120}$ and patient self-reporting. Although self-reporting by patients has been considered to overestimate adherence by about $10 \%-20 \%,{ }^{121}$ it can be a reliable indicator if problems are reported, and it presents an opportunity for intervention to assist the patient. The pharmacist's inquiries about adherence should be phrased in a nonjudgmental, routine manner, through open-ended questions that acknowledge the difficulty of perfect adherence. ${ }^{122}$ The pharmacist should ascertain not only whether doses are being missed but also the patient's knowledge of medication names and prescribed dosing regimen, including attention to dietary requirements, and whether there may be a pattern to any nonadherence, for example, on weekends or when daily routines change. ${ }^{123}$ This aspect of care will become even more crucial as the HIV-infected population ages and the pill burden increases with polypharmacy for treating comorbidities of aging. Reasons for poor adherence should be explored and potential solutions may be proposed.

Medication adherence should be regarded as a behaviour that patients adopt and incorporate into their lifestyles. Pharmacists can support adherence by helping to anticipate and identify barriers to adherence and strategizing with patients to find solutions that will work for them ${ }^{104}$ (Appendix 1). Options and effective strategies may include utilization of once-daily regimens, single-tablet fixed-dose combinations, reminder alarm devices, texting services, pill organizers, dose planners, and one-on-one support in a multidisciplinary team environment.

\subsection{Acquisition of Medications}

One of the few health care professionals likely to have access to information about the acquisition of medications and payment plans is the pharmacist. Antiretrovirals can be cost prohibitive, and the cost may be a significant barrier to achieving therapeutic success. As HIV-infected patients age and begin adding medications for the treatment of comorbid illnesses, the burden of added costs rises significantly. The patient's ability to pay for medications should be well established before combination antiretroviral therapy is initiated; otherwise, inconsistent access will result in therapy gaps and increase the risk of drug resistance.

If the financial burden of prescription drugs is overwhelming, other areas of a patient's life may be compromised, such as nutrition, stable housing, social interaction, and overall quality of life. Pharmacists should be aware of the various drug benefit programs that can assist patients with high prescription costs, including federal programs available to special patient groups, such as the Ryan White HIV/AIDS Program in the United States, for low-income, uninsured, or indigent patients, and the Non-Insured Health Benefits program in Canada, for First Nations and Inuit patients. Pharmacists should also be mindful of other means of accessing medication, such as participating in clinical drug trials or enrolling in emergencyrelease, compassionate-access, and expanded-access programs. Pharmacists should also become familiar with local advocacy groups that offer financial assistance to manage drug costs. Pharmacists can assist in selecting affordable medications and/or recommending effective therapeutic alternatives based on their awareness of the particulars of a patient's drug insurance plan. Pharmacists should become skilled at coordinating benefits to maximize the potential for full coverage. At the same time, patients should understand the importance of maintaining a commitment to one pharmacy that can best serve their needs and provide services with fees that are within patients' respective budgets. Patients should also be advised that their community pharmacy may not routinely stock all the medications they require, and they may need to provide advance notice of refills to ensure an uninterrupted supply of medications.

\section{Monitoring Response to Therapy 4.1 Managing Adverse Drug Reactions}

Adverse drug reactions to antiretrovirals occur frequently and are a major reason for discontinuing or changing therapy. ${ }^{124}$ Almost all organ systems can be affected by combination antiretroviral therapy, including the gastrointestinal system, heart, bone, kidneys, and liver. ${ }^{2}$ Adverse events may present as severe and/or serious events, which are relatively infrequent, or as less serious but more common events. ${ }^{125}$ The serious adverse effects of antiretrovirals include hypersensitivity reactions, mitochondrial toxicity resulting in lactic acidosis, cardiomyopathy, pancreatitis, steatohepatitis, and nephrotoxicity. Lipodystrophy syndrome, including changes in fat distribution, may develop with long-term use of antiretrovirals (particularly with exposure to thymidine nucleoside analogues) and may be associated with significant psychological stress and stigmatization. These events typically require discontinuation of therapy, and in most cases rechallenge is not recommended. ${ }^{2}$ In con- 
trast, more common and generally less severe adverse effects include diarrhea, nausea, headache, CNS effects, and grade 1-2 cutaneous rashes. In some cases, adverse effects resolve on their own. Adverse effects can also be effectively managed by the addition of symptomatic treatment or by changing the regimen of antiretrovirals. ${ }^{1,126}$ Additional risk factors that may compound the risk of long-term toxic effects, such as substance use, alcohol, smoking, and lifestyle factors, should also be routinely addressed at clinic visits.

Adding to the complexity of adverse drug reactions is the rapidly evolving field of pharmacogenetics. ${ }^{127}$ For example, there is a higher prevalence of abacavir hypersensitivity reactions among individuals who carry the class I allele $H L A$ $B * 5701 .{ }^{128}$ Use of immunogenetic testing to screen for abacavir hypersensitivity reaction (by identifying the presence of $H L A$ $\left.B^{*} 5701\right)$ is now standard of care. ${ }^{1}$ Other drugs that are under study for genetic variability in disposition and associated toxicity include nevirapine (hypersensitivity), ${ }^{129}$ efavirenz (CNS effects), ${ }^{130}$ and tenofovir (renal dysfunction). ${ }^{131}$

In the initial assessment of an adverse drug reaction, it is critical to evaluate the patient's signs and symptoms, the type of reaction (acute or chronic, dose-related or idiosyncratic), the timing of onset of the event, any underlying organ dysfunction, concomitant diseases, and any other abnormal laboratory results. A thorough history of drug and substance use and allergies, along with an assessment of adherence with therapy, duration of therapy, and possible drug interactions, is also required. Once a potential causative drug is identified, management may include addition of a new drug to treat the adverse effect, discontinuation of the suspect drug, and/or substitution with another less toxic but equally effective agent. ${ }^{125}$ Although adverse drug reactions occurring with other drug classes can sometimes be managed effectively by reducing the dosage of the causative agent, reducing the dosage of antiretrovirals in patients with normal renal and hepatic function is generally not recommended because of the possible development of resistance. Readers are referred to several current references that review the toxicity of antiretrovirals in more depth. ${ }^{1,2,132}$

\subsection{Therapeutic Drug Monitoring}

Therapeutic drug monitoring involves measurement of drug concentrations in the plasma and subsequent adjustment of doses to achieve therapeutic concentrations. Evidence exists of a relationship between exposure to antiretrovirals and virologic response and, in more limited instances, between drug exposure and toxicity. ${ }^{133,134}$ Therapeutic drug monitoring is therefore used to optimize the efficacy and, in certain cases, to minimize the toxic effects of antiretrovirals. Several retrospective studies have demonstrated correlations between plasma concentrations of various antiretrovirals and specific toxic effects. In particular, indinavir and nephrolithiasis, efavirenz and CNS toxicity, nevirapine and hepatotoxicity, atazanavir and hyperbilirubinemia, and lopinavir and dyslipidemia. ${ }^{135,136}$

The clinical application of therapeutic drug monitoring has been evaluated in a few prospective randomized trials involving patients receiving their first course of combination antiretroviral therapy. ${ }^{137,138}$ The results of these studies support the utility of such monitoring in achieving positive virologic outcomes and/or minimizing drug toxicity in this population. However, prospective studies have failed to demonstrate the benefit of therapeutic drug monitoring in improving clinical outcomes in treatment-experienced patients. ${ }^{139-142}$ The use of suboptimal target concentrations, delayed use of therapeutic drug monitoring, low adherence by physicians to recommendations for dose adjustment, inclusion of patients with highly treatment-resistant virus, and insufficient statistical power are reasons that might explain the lack of benefit of therapeutic drug monitoring in these studies. ${ }^{13,136}$

Therapeutic drug monitoring for antiretrovirals is likely to be most helpful when used for specific patient populations and clinical scenarios. For instance, pediatrics, pregnancy, aging, hepatic impairment, and obesity or cachexia may be associated with changes in pharmacokinetic parameters that can affect absorption, metabolism, and clearance of drugs. ${ }^{143}$ Therapeutic drug monitoring may also be useful in evaluating suspected drug interactions, malabsorption, toxicity of certain antiretrovirals, virologic failure, and use of unboosted protease inhibitors or unconventional regimens that may be associated with a risk of suboptimal trough concentrations. ${ }^{144}$ Therapeutic drug monitoring can also be a valuable clinical tool, especially when combined with other important treatment considerations as part of overall clinical management of a patient. In some countries, therapeutic drug monitoring is part of routine standard of care, whereas in other countries, it is performed only by request or in the course of research programs.

\section{Guiding Transitions of Care}

\subsection{Prevention of Errors}

Like other patients with complex medical needs, many patients living with HIV/AIDS are under the care of multiple health care providers in various settings. In many cases, a patient's HIV disease may be managed through a specialized clinic, with other medical issues being handled by a general practitioner (GP) or other specialists. Medication errors occur frequently in individuals with HIV/AIDS, often as a result of faulty communication at the interfaces of care, such as admission to and discharge from hospital. ${ }^{145,146}$ Antiretroviral prescribing errors have been estimated to occur for between 5\% and $30 \%$ of HIV-infected hospital inpatients, ${ }^{8,147}$ with one prospective study reporting a prevalence as high as $72 \%{ }^{148}$ These errors have included prescribing an incorrect drug, incorrect doses or dosing frequencies, drug-drug interactions, omission of a needed drug, and duplicate therapy., ${ }^{8 / 14-149}$ Antiretroviral errors also occur in the ambulatory setting, ${ }^{150,151}$ 
including specialized clinics, ${ }^{152}$ and may occur as a result of actions by both patients and health care providers. ${ }^{13,154}$

\subsection{Medication Reconciliation}

Medication reconciliation, the process of obtaining the most accurate list of all medications that a patient is taking and comparing this list against the physician's admission, transfer, and/or discharge orders, ${ }^{155}$ can help to identify discrepancies and thus can significantly reduce the incidence of errors. Although medication reconciliation is a shared responsibility, pharmacists should strongly consider leadership in this area, ${ }^{156}$ as studies have shown they can be an instrumental component of the process. Obtaining an accurate (best possible) medication history through reviews of patient-related documents from GP care, specialist interventions, and hospital reports is essential; patient interviews and comparison with pharmacy medication profiles are then used to confirm treatment information. Many studies have shown that more information is obtained when the medication history is collected by a pharmacist rather than another health care provider. ${ }^{145}$ Furthermore, when clinical pharmacists were actively involved in or leading the medication evaluation of HIV-positive patients being admitted to hospital, medication errors were prevented, error rates were further reduced, and the duration of uncorrected errors was significantly shorter. ${ }^{8,149,157,158}$ Pharmacists can also be useful resources for residents and physicians, especially those with limited experience in HIV, who may be more prone to antiretroviral prescribing errors. ${ }^{159,160}$ Pharmacists can provide advice regarding dosage adjustments to address drug interactions or organ insufficiencies, can suggest alternatives if current therapies or formulations are unsuitable or contraindicated, and can ensure that complete regimens are prescribed, including comedications, problems that a computerized physician order entry system is unlikely to be able to identify or help resolve.

Pharmacists should also consider becoming involved in the discharge process. Unintentional medication discrepancies frequently occur at hospital discharge and have the potential to cause patient discomfort and/or clinical deterioration. ${ }^{14,161}$ Receiving incorrect prescriptions at the time of discharge may lead to patients taking inadequate antiretroviral regimens until follow-up, which places them at risk for drug resistance. If prophylactic medications are omitted from discharge prescriptions, immunocompromised patients may be left vulnerable to opportunistic infections. When possible, pharmacists should review the discharge medication list for accuracy and completeness, to ensure that it accounts for all of the patient's admission medications, any changes made during the hospital stay, and any new medications that are to be continued after discharge. This comprehensive list should then be reviewed with the patient to ensure understanding. ${ }^{162}$ This process may allow patients to help in minimizing medication errors, by recognizing when they have been given incorrectly or incompletely prescribed antiretrovirals or other drugs. Sharing discharge medication information with the patient's other caregivers, including the family doctor, the HIV physician, and/or community and clinic pharmacists, will also minimize confusion and facilitate provision of seamless care.

\subsection{Seamless Care}

Seamless care is the desirable continuity of care delivered to a patient in the health care system across the spectrum of caregivers and their environments. ${ }^{163}$ Traditionally, seamless care initiatives have focused on the patient's transfer from acute care back to the community. ${ }^{164}$ Similarly in HIV practice, documentation of medical changes generally tends to flow from HIV and other specialists to the patient's family physician. However, valuable patient information regarding past medication use, adherence, and use of nonprescription medications can be provided by community practitioners to specialty practitioners. Providers working in rehabilitation or continuing care facilities, home care services, and other environments should also ideally be integrated into a seamless care network. ${ }^{164}$

Without a seamless care process, incomplete communication regarding adjustment of combination antiretroviral therapy or initiation and discontinuation of medications may lead to unrecognized and undermanaged drug interactions or adverse effects. For example, a patient may have a prescription for a corticosteroid inhaler from his GP and may subsequently experience Cushing syndrome secondary to a drug interaction with HIV protease inhibitors. ${ }^{165}$ A GP unfamiliar with this drug interaction might treat the patient's condition inappropriately, potentially leading to further complications, poor outcomes, and increased cost to the health care system.

There is also a need for efficient communication and case coordination to avoid unnecessary duplication of services and to minimize discrepancies in drug therapies and care plans. ${ }^{160}$ Patients, their family or other caregivers, and their physicians should be encouraged to consult with the HIV pharmacist if any treatment changes are being considered. By being involved in the many aspects of medication assessment and review, pharmacists may help to mitigate error rates and reduce harm through medication reconciliation and seamless care programs, thus helping patients to achieve the optimal benefits of combination antiretroviral therapy.

\section{Scholarly and Professional Activities 6.1 Drug Information}

Information about HIV changes rapidly, making it a challenge for both patients and health care providers to stay current. In terms of patient education, pharmacists need to tailor information to the degree of understanding and education of the individual patient. Some patients may have no knowledge whatsoever about HIV, whereas others may have a good understanding about their prescription and nonprescription medications and may access treatment information from 
sources such as the internet and HIV/AIDS associations. In this situation, the health care practitioner is often in a position to learn from the patient rather than providing education. This role reversal may initially be difficult for some health care providers. However, the pharmacist is encouraged to engage in interactive dialogue with the patient while ensuring that the resources the patient has consulted are reliable, accurate, and current. For internet websites, users should consider whether the authors' credentials are clearly stated and whether the website is affiliated with a recognized academic or health care institution. Users might also ask whether sources of funding for the website are clearly stated, whether the information is well referenced, and when the website was last updated. Internet blogs, chat rooms, and social networking groups are open forums for discussion, but they may or may not be moderated. It can also be difficult to verify the credibility of the participants, and the information or experiences shared may be biased by participants' background or experiences.

The vast amount of information about HIV treatment that is currently available can be intimidating, even for health care practitioners practising specifically in this area. An extensive array of drug information resources is available for pharmacists to consult, and it is important to recognize the advantages and limitations of these various references. For instance, textbooks are often written by recognized authorities in the field, and the information is usually well referenced, but it may be outdated. Randomized controlled studies published in reputable scientific journals have undergone a stringent peer-review process before publication, so they tend to be reliable and may be more up to date than textbooks. Nonetheless, sources of potential bias such as involvement of a drug manufacturer and authors' conflicts of interest should be clearly identified. The reader should carefully review details regarding the study population and methodology to determine how the results may be extrapolated and best applied in clinical practice. Abstracts and summary reports from scientific conferences often represent the most current, state-of-the-art information on HIV therapeutics and pharmacology, but these data sometimes reflect only short-term results, and complete details regarding the research design may not be provided.

\subsection{Research}

The treatment of HIV infection involves a steady cycle of development, testing, and approval of new drugs. ${ }^{1}$ Therapy is complicated by incomplete knowledge of new antiretrovirals entering the market, since licensing trials often fall short of answering all questions about a drug's rational use in clinical practice. ${ }^{167-170}$ As such, unanswered clinical questions must be addressed after the medication has been approved for widespread use. ${ }^{167-170}$ As clinical front-line providers and appraisers of the literature, pharmacists can identify key gaps in the evidence-based literature, define important new research questions, and contribute to the generation of new drug-related knowledge in the field of HIV therapeutics.

Pharmacists should be aware that important research findings can result from many different types of research. The definition of what constitutes research is very broad and may include articles as simple as case reports or as complex as multicentre controlled trials. Many types of research can be conducted by pharmacists specializing in HIV, including but not limited to case reports of adverse drug reactions; studies of adherence patterns and methods of support, drug use patterns and prescribing practices, therapeutic drug monitoring, pharmacokinetics, pharmacogenomics, drug interactions, health economics, drug policy development, quality of life, and pharmacoepidemiology; health services research; and interventional trials on the management of HIV or HIV-related complications.

In view of the close professional collaborative relationships that already exist among pharmacists, physicians, and other members of the health practitioner team, it may be beneficial to extend these collaborative relationships to the research process. Additionally, to aid pharmacists who are less experienced or uncomfortable with the idea of performing research, a circle of research mentors who could review and advise the research process from a methodologic perspective should be established. Pharmacists who are interested in developing a more substantial research portfolio may wish to seek out additional research training opportunities in the areas of pharmacoepidemiology, pharmacology, or pharmacoeconomics.

In summary, there are many opportunities for pharmacists to get involved in research. While the demands of clinical practice may leave many pharmacists feeling too busy or intimidated to get involved in research, many different types of research can be valuable, adding to existing knowledge about drugs, improving health outcomes for individuals living with HIV infection, and ultimately advancing the role of clinical pharmacists. ${ }^{171}$

\subsection{Professional Networking and Collaboration}

Centres specializing in HIV care are often concentrated in large, urban settings, and because of overall disease characteristics and population demographics, the number of pharmacists working in HIV-related care is relatively small compared with the number practising in other common specialties, such as cardiovascular care, nephrology, or diabetes. As such, HIV pharmacists may be practising in relative geographic isolation from their colleagues. Establishing professional networks allows pharmacists in small or isolated practices to exchange "clinical pearls" and practice insights with colleagues, to share new information, to develop common educational projects and tools, and to pool resources and data to conduct research that otherwise might not be achievable on a smaller scale.

In Canada, the Canadian HIV/AIDS Pharmacists Network/Association canadienne des pharmaciens en 
VIH/SIDA (CHAP) (www.hivclinic.ca/chap) was formed in January 1997, with the mission of bringing together pharmacists with a clinical and research focus in HIV/AIDS in order to optimize patient outcomes and promote the profession of pharmacy through communication, education, research, and clinical practice. ${ }^{172} \mathrm{CHAP}$ members meet annually, communicate regularly by e-mail, and collaborate on a variety of projects and publications. CHAP has now expanded to include HIV pharmacy practitioners from the United States, the United Kingdom, South Africa, and Australia, and an international network of HIV pharmacists is currently being explored.

\subsection{Certification and Credentialling Programs}

The number of specialized HIV pharmacists who possess the clinical acumen and broad drug expertise to significantly contribute to patient care, education, professional development, and research has grown in recent years. In the United States, the American Academy of HIV Medicine has been certifying HIV care providers with HIV Specialist (AAHIVS) or HIV Expert (AAHIVE) designations since 2002. In addition, the Academy recently launched its new HIV Pharmacist (AAHIVP) certification program. ${ }^{173}$ Similar to the other certifications offered by this organization, the AAHIVP program is a 2-year, renewable credential for pharmacists who meet strict experience and continuing education requirements and who pass a comprehensive examination on all aspects of HIV-related pharmaceutical care. The goals of the AAHIVP program include providing a meaningful and defensible professional development opportunity and establishing a minimum standard of knowledge in HIV pharmacy. The program is open to international providers, including Canadian pharmacists.

\section{CONCLUSIONS}

Pharmacists caring for HIV/AIDS patients in the hospital or in the community and other ambulatory settings have an integral role in patient care and can have a significant, positive impact on patient outcome. Given the expanding scope of HIV disease management, pharmacists need to be knowledgeable about all aspects of pharmacology and patient care related to treatment of HIV, as well as other infections; non-infectious, lifestyle, and/or ageing-related comorbidities; and other conditions. As new information becomes available and as patients age, pharmacists' role in the care of these patients must also continue to evolve.

\section{References}

1. Panel on Antiretroviral Guidelines for Adults and Adolescents. Guidelines for the use of antiretroviral agents in HIV-infected adults and adolescents. Rockville (MD): US Department of Health and Human Services; 2012 Mar 27 [cited 2012 Apr 3]. Available from: http://aidsinfo.nih.gov/ contentfiles/adultandadolescentgl.pdf

2. Calmy A, Hirschel B, Cooper DA, Carr A. A new era of antiretroviral drug toxicity. Antivir Ther 2009;14(2):165-179.

3. Scott JD, Abernathy KA, Diaz-Linares M, Graham KK, Lee JC. HIV clinical pharmacists-the US perspective. Farm Hosp 2010;34(6):303-308.
}

4. Henderson KC, Hindman J, Johnson SC, Valuck RJ, Kiser JJ. Assessing the effectiveness of pharmacy-based adherence interventions on antiretroviral adherence in persons with HIV. AIDS Patient Care STDs 2011;25(4):221228.

5. Ma A, Chen D, Chau F, Saberi P. Improving adherence and clinical outcomes through an HIV pharmacist's interventions. AIDS Care 2010;22(10): 1189-1194.

6. March K, Mak M, Louie SG. Effects of pharmacists' interventions on patient outcomes in an HIV primary care clinic. Am J Health Syst Pharm 2007;64(24):2574-2578

7. Merchen BA, Gerzenshtein L, Scarsi KK, Achenbach C, Postelnick M, Zavod RM, et al. HIV-specialized pharmacists' impact on prescribing errors in hospitalized patients on antiretroviral therapy [abstract H2-794]. 51 st Interscience Conference on Antimicrobial Agents and Chemotherapy; 2011 Sep 17-20; Chicago (IL).

8. Heelon M, Skiest D, Tereso G, Meade L, Weeks J, Pekow P, et al. Effect of a clinical pharmacist's intervention on duration of antiretroviral-related errors in hospitalized patients. Am J Health Syst Pharm 2007;64(19): 2064-2068.

9. Tailor SAN, Foisy MM, Tseng A, Beardsall A, Ostrop N, Khaliq K, et al; for the Canadian Collaborative HIV/AIDS Pharmacy Network. The role of the pharmacist caring for people living with HIV/AIDS: a Canadian position paper. Can J Hosp Pharm 2000;53(2):92-103.

10. American Society of Health-System Pharmacists. ASHP statement on the pharmacist's role in the care of patients with HIV infection. Am J Health Syst Pharm 2003;60(19):1998-2003.

11. International Pharmaceutical Federation; World Health Organization. The role of the pharmacist in the fight against the HIV-AIDS pandemic. A joint declaration between the World Health Organization (WHO) and the International Pharmaceutical Federation (FIP). Geneva (Switzerland): World Health Organization; 1997.

12. Thompson MA, Aberg JA, Cahn P, Montaner JSG, Rizzardini G, Telenti A, et al. Antiretroviral treatment of adult HIV infection: 2010 recommendations of the International AIDS Society-USA Panel. JAMA 2010;304(3):321-333.

13. Guidelines for the clinical management and treatment of HIV infected adults in Europe. Version 6. Paris (France): European AIDS Clinical Society; 2011 Oct [cited 2012 Mar 21]. 61 pp. Available from: www. europeanaidsclinicalsociety.org/images/stories/EACS-Pdf/eacsguidelinesv6_english.pdf

14. Nelson M, Dockrell DH, Edwards S, on behalf of the BHIVA Guidelines Subcommittee. British HIV Association and British Infection Association guidelines for the treatment of opportunistic infection in HIV-seropositive individuals 2011. HIV Med 2011;12(Suppl 2):1-144.

15. Centers for Disease Control and Prevention. Guidelines for prevention and treatment of opportunistic infections in HIV-infected adults and adolescents. MMWR 2009 Mar 24;58:1-209.

16. Hirsch MS, Günthard HF, Schapiro JM, Brun-Vézinet F, Clotet B, Hammer SM, et al. Antiretroviral drug resistance testing in adult HIV-1 infection: 2008 recommendations of an International AIDS Society-USA panel. Clin Infect Dis 2008;47(2):266-285.

17. Paredes R, Clotet B. Clinical management of HIV-1 resistance. Antiviral Res 2010;85(1):245-265.

18. Frenkel LM, Tobin NH. Understanding HIV-1 drug resistance. Ther Drug Monit 2004;26(2):116-121.

19. Grant PM, Zolopa AR. The use of resistance testing in the management of HIV-1-infected patients. Curr Opin HIV AIDS 2009;4(6):474-480.

20. Buchacz K, Baker RK, Palella FJJ, Chmiel JS, Lichtenstein KA, Novak RM, et al. AIDS-defining opportunistic illnesses in US patients, 1994-2007: a cohort study. AIDS 2010;24(10):1549-1559.

21. Vance DE, Mugavero M, Willig J, Raper JL, Saag MS. Aging with HIV: a cross-sectional study of comorbidity prevalence and clinical characteristics across decades of life. J Assoc Nurses AIDS Care 2010;22(1):17-25.

22. Evans-Jones JG, Cottle LE, Back DJ, Gibbons S, Beeching NJ, Carey PB, et al. Recognition of risk for clinically significant drug interactions among HIV-infected patients receiving antiretroviral therapy. Clin Infect Dis 2010; 50(10):1419-1421.

23. Marzolini C, Elzi L, Gibbons S, Weber R, Fux C, Furrer H, et al. Prevalence of comedications and effect of potential drug-drug interactions in the Swiss HIV Cohort Study. Antivir Ther 2010;15(3):413-423.

24. Patel N, Abdelsayed S, Veve M, Miller CD. Predictors of clinically significant drug-drug interactions among patients treated with nonnucleoside reverse transcriptase inhibitor-, protease inhibitor-, and raltegravir-based antiretroviral regimens. Ann Pharmacother 2011;45(3):317-324.

25. Marzolini C, Back D, Weber R, Furrer H, Cavassini M, Calmy A, et al. Ageing with HIV: medication use and risk for potential drug-drug interactions. J Antimicrob Chemother 2011;66(9):2107-2111. 
26. Hill A, van der Lugt J, Sawyer W, Boffito M. How much ritonavir is needed to boost protease inhibitors? Systematic review of 17 dose-ranging pharmacokinetic trials. AIDS 2009;23(17):2237-2245.

27. Fulco PP, Hynicka L, Rackley D. Raltegravir-based HAART regimen in a patient with large B-cell lymphoma. Ann Pharmacother 2010; 44(3):377-382.

28. Tricot L, Teicher E, Peytavin G, Zucman D, Conti F, Calmus Y, et al. Safety and efficacy of raltegravir in HIV-infected transplant patients cotreated with immunosuppressive drugs. Am J Transplant 2009;9(8):1946-1952.

29. Isentress (raltegravir) prescribing information. Kirkland (QC): Merck Frosst Canada Ltd; 2009

30. Zembruski NC, Büchel G, Jödicke L, Herzog M, Haefeli WE, Weiss J. Potential of novel antiretrovirals to modulate expression and function of drug transporters in vitro. J Antimicrob Chemother 2011;66(4):802-812.

31. Mathias AA, West S, Hui J, Kearney BP. Dose-response of ritonavir on hepatic CYP3A activity and elvitegravir oral exposure. Clin Pharmacol Ther 2009;85(1):64-70

32. Barrios A, Rendón A, Negredo E, Barreiro P, Garcia-Benayas T, Labarga P, et al. Paradoxical CD4+ T-cell decline in HIV-infected patients with complete virus suppression taking tenofovir and didanosine. AIDS 2005;19(6):569-575.

33. Negredo E, Moltó J, Burger D, Viciana P, Ribera E, Parades R, et al. Unexpected CD4 cell count decline in patients receiving didanosine and tenofovir-based regimens despite undetectable viral load. AIDS 2004; 18(3):459-463.

34. Ray AS, Olson L, Fridland A. Role of purine nucleoside phosphorylase in interactions between 2',3'-dideoxyinosine and allopurinol, ganciclovir or tenofovir. Antimicrob Agents Chemother 2004;48(4):1089-1095.

35. Pau AK, Boyd SD. Recognition and management of significant drug interactions in HIV patients: challenges in using available data to guide therapy. Clin Pharmacol Ther 2010;88(5):712-719.

36. Sheehan NL, Kelly DV, Tseng AL, van Heeswijk RP, Béique LC, Hughes CA; Canadian HIV/AIDS Pharmacists Network. Evaluation of HIV drug interaction web sites. Ann Pharmacother 2003;37:1577-1586.

37. Krakower D, Kwan CK, Yassa DS, Colvin RA. iAIDS: HIV-related internet resources for the practicing clinician. Clin Infect Dis 2010;51(7):813-822.

38. Park-Wyllie L, Levine MA, Holbrook A, Thabane L, Antoniou T, Yoong $\mathrm{D}$, et al. Outcomes of dosage adjustments used to manage antiretroviral drug interactions. Clin Infect Dis 2007;45(7):933-936.

39. Littlewood RA, Vanable PA. Complementary and alternative medicine use among HIV-positive people: research synthesis and implications for HIV care. AIDS Care 2008;20(8):1002-1018.

40. Duggan J, Peterson WS, Schutz M, Khuder S, Charkraborty J. Use of complementary and alternative therapies in HIV-infected patients. AIDS Patient Care STDs 2001:15(3):159-167.

41. van den Bout-van den Beukel CJP, Koopmans PP, van der Ven AJAM, De Smet PAGM, Burger DM. Possible drug metabolism interactions of medicinal herbs with antiretroviral agents. Drug Metab Rev 2006;38(3):477-514

42. Wiegman DJ, Brinkman K, Franssen EJF. Interaction of Gingko biloba with efavirenz. AIDS 2009;23(9):1184-1185.

43. van den Bout-van den Beukel CJP, Bosch MEW, Burger D, Koopmans PP, van der Ven AJAM. Toxic lopinavir concentrations in an HIV-1 infected patient taking herbal medications. AIDS 2008;22(10):1243-1244.

44. Kassler W, Blanc P, Greenblatt R. The use of medicinal herbs by human immunodeficiency virus-infected patients. Arch Intern Med 1991; 151(11):2281-2288.

45. SungHee Kole A, Jones H, Christensen R, Gladstein J. A case of Kombucha tea toxicity. J Intensive Care Med 2009;24(3):205-207.

46. Dangerous supplements: what you don't know about these 12 ingredients could hurt you. Consum Rep 2010;75(9):16-20.

47. Dasgupta A. Herbal supplements and therapeutic drug monitoring: focus on digoxin immunoassays and interactions with St. John's wort. Ther Drug Monit 2008;30(2):212-217.

48. Saag MS. HIV now firmly established in the middle ages. Clin Infect Dis 2011;53(11):1140-1142

49. El-Ibiary SY, Cocohoba JM. Effects of HIV antiretrovirals on the pharmacokinetics of hormonal contraceptives. Eur J Contracept Reprod Health Care 2008;13(2):123-132.

50. Panel on Treatment of HIV-Infected Pregnant Women and Prevention of Perinatal Transmission. Recommendations for use of antiretroviral drugs in pregnant HVI-1-infected women for maternal health and interventions to reduce perinatal HIV transmission in the United States. US Department of Health and Human Services, National Institutes of Health; 2011 Sep 14 [cited 2012 Mar 16]. 207 pp. Available from: http://aidsinfo.nih.gov/ ContentFiles/PerinatalGL.pdf

51. Koren G, Nulman I, Aleksa K, Gareri J, Einarson A, Ito S. Essay for the 2011 CIHR/CMAJ award: Motherisk — caring for mothers, protecting the unborn. CMAJ 2012;184(2):E155-E157.
52. Panel on Antiretroviral Therapy and Medical Management of HIV-Infected Children. Guidelines for the use of antiretroviral agents in pediatric HIV infection. US National Institutes of Health, Health Resources and Services Administration; 2011 Aug 11 [cited 2012 Mar 16]. 268 pp. Available from: http://aidsinfo.nih.gov/ContentFiles/PediatricGuidelines.pdf

53. Anderson GD, Lynn AM. Optimizing pediatric dosing: a developmental pharmacologic approach. Pharmacotherapy 2009;29(6):680-690.

54. Jullien V, Urien S, Hirt D, Delaugerre C, Rey E, Teglas J, et al. Population analysis of weight-, age-, and sex-related differences in the pharmacokinetics of lopinavir in children from birth to 18 years. Antimicrob Agents Chemother 2006;50(11):3548-3555.

55. Chadwick EG, Pinto J, Yogev R, Alvero CG, Hughes MD, Palumbo P, et al.; International Maternal Pediatric Adolescent Clinical Trials Group (IMPAACT) P1030 Team. Early initiation of lopinavir/ritonavir in infants less than 6 weeks of age: pharmacokinetics and 24-week safety and efficacy. Pediatr Infect Dis J 2009;28(3):215-219.

56. Saitoh A, Fletcher CV, Brundage R, Alvero C, Fenton T, Hsia K, et al. Efavirenz pharmacokinetics in HIV-1-infected children are associated with CYP2B6-G516T polymorphism. J Acquir Immune Defic Syndr 2007; 45(3):280-285

57. Nso A, Larru B, Bellón J, Mellado M, Ramos T, González M, et al Comparison of levels of antiretroviral drugs with efficacy in children with HIV infection. Indian J Pediatr 2010;77(4):397-402.

58. Rodriguez W, Selen A, Avant D, Chaurasia C, Crescenzi T, Gieser G, et al Improving pediatric dosing through pediatric initiatives: what we have learned. Pediatrics 2008;121(3):530-539.

59. Kaletra (lopinavir/ritonavir) prescribing information. Saint-Laurent (QC): Abbott Laboratories Limited Canada; 2010

60. Chubaty A, Hughes C, Hills-Nieminen C. Crushing antiretrovirals Toronto (ON): Toronto General Hospital; 2008 [cited 2010 Oct 29]. Available from: www.hivclinic.ca/main/drugs_extra_files/crushing\% 20ARVs_C\%20Hughes.pdf

61. Dayneka N. Teen challenge: promoting medication adherence in adolescents with chronic disease. Pharm Pract 2010;26(7):59-67,71,92.

62. Koenig LJ, Nesheim S, Abramowitz S. Adolescents with perinatally acquired HIV: emerging behavioral and health needs for long-term survivors. Curr Opin Obstet Gynecol 2011;23(5):321-327.

63. Reisner SL, Mimiaga MJ, Skeer M, Perkovich B, Johnson CV, Safren SA A review of HIV antiretroviral adherence and intervention studies among HIV-infected youth. Top HIV Med 2009;17(1):14-25.

64. Butler AM, Williams PL, Howland LC, Storm D, Hutton N, Seage GR 3rd; Pediatric AIDS Clinical Trials Group 219C Study Team. Impact of disclosure of HIV infection on health-related quality of life among children and adolescents with HIV infection. Pediatrics 2009;123(3):935-943.

65. Dowshen N, D'Angelo L. Health care transition for youth living with HIV/AIDS. Pediatrics 2011;128(4):762-771.

66. Justice AC. HIV and aging: time for a new paradigm. Curr HIVIAIDS Rep 2010;7(2):69-76

67. Deeks SG. Accelerated aging in HIV infection. Top HIV Med 2009;17(4):118-123

68. Wand H, Calmy A, Carey DL, Samaras K, Carr A, Law MG, et al.; INITIO Trial International Coordinating Committee. Metabolic syndrome, cardiovascular disease and type 2 diabetes mellitus after initiation of antiretroviral therapy in HIV infection. AIDS 2007;21(18):2445-2453.

69. D’Agostino RB Sr, Vasan RS, Pencina MJ, Wolf PA, Cobain M, Massaro $\mathrm{JM}$, et al. General cardiovascular risk profile for use in primary care: the Framingham Heart Study. Circulation 2008;117(6):743-753.

70. Genest J, McPherson R, Frohlich J, Anderson T, Campbell N, Carpentier A, et al. 2009 Canadian Cardiovascular Society/Canadian guidelines for the diagnosis and treatment of dyslipidemia and prevention of cardiovascular disease in the adult: 2009 recommendations. Can J Cardiol 2009;25(10):567-579.

71. Canadian Diabetes Association Clinical Practice Guidelines Expert Committee. Canadian Diabetes Association 2008 clinical practice guidelines for the prevention and management of diabetes in Canada. Can J Diabetes 2008;32 Suppl 1:S1-S201.

72. Brown TT, Qaqish RB. Antiretroviral therapy and the prevalence of osteopenia and osteoporosis: a meta-analytic review. AIDS 2006;20(17):2165-2174

73. Mueller N, Fux C, Ledergerber B, Elzi L, Schmid P, Dang T, et al. High prevalence of severe vitamin $\mathrm{D}$ deficiency in combined antiretroviral therapy-naive and successfully treated Swiss HIV patients. AIDS 2010;24(8):1127-1134.

74. Hanley DA, Cranney A, Jones G, Whiting SJ, Leslie WD, for the Guidelines Committee of the Scientific Advisory Council of Osteoporosis Canada. Vitamin D in adult health and disease: a review and guidelines statement from Osteoporosis Canada (summary). CMAJ 2010; 182(12):1315-1319. 
75. McComsey GA, Tebas P, Shane E, Yin MT, Overton ET, Huang JS, et al Bone disease in HIV infection: a practical review and recommendations for HIV care providers. Clin Infect Dis 2010;51(8):937-946.

76. Holick MF, Binkley NC, Bischoff-Ferrari HA, Gordon CM, Hanley DA, Heaney RP, et al. Evaluation, treatment, and prevention of vitamin D deficiency: an Endocrine Society clinical practice guideline. J Clin Endocrinol Metab 2011;96(7):1911-1930.

77. Welz T, Childs K, Ibrahim F, Poulton M, Taylor CB, Moniz CF, et al. Efavirenz is associated with severe vitamin D deficiency and increased alkaline phosphatase. AIDS 2010;24(12):1923-1928.

78. Papaioannou A, Morin S, Cheung AM, Atkinson S, Brown JP, Feldman S, et al.; Scientific Advisory Council of Osteoporosis Canada. 2010 clinical practice guidelines for the diagnosis and management of osteoporosis in Canada: summary. CMAJ 2010;182(17):1864-1873.

79. Negredo E, Martinez-López E, Paredes R, Rosales J, Pérez-Alvarez N, Holgado $S$, et al. Reversal of HIV-1-associated osteoporosis with once-weekly alendronate. AIDS 2005;19(3):343-345.

80. Letendre S, Ellis R, Ances B, McCutchan J. Neurologic complications of HIV disease and their treatment. Top HIV Med 2010;18(2):45-55.

81. Kaplan JE, Benson C, Holmes KH, Brooks JT, Pau A, Masur H, et al. Guidelines for prevention and treatment of opportunistic infections in HIV-infected adults and adolescents: recommendations from CDC, the National Institutes of Health, and the HIV Medicine Association of the Infectious Diseases Society of America. MMWR Recomm Rep 2009;58 (RR-4):1-207

82. European AIDS Treatment Network (NEAT) Acute Hepatitis C Infection Consensus Panel. Acute hepatitis C in HIV-infected individuals: recommendations from the European AIDS Treatment Network (NEAT) consensus conference. AIDS 2011;25(4):399-409.

83. McMahon MA, Jilek BL, Brennan TP, Shen L, Zhou Y, Wind-Rotolo M, et al. The HBV drug entecavir - effects on HIV-1 replication and resistance. N Engl J Med 2007;356(25):2614-2621.

84. Jain MK, Zoellner CL. Entecavir can select for M184V of HIV-1: a case of an HIV/hepatitis B (HBV) naïve patient treated for chronic HBV. AIDS 2007;21(17):2365-2366

85. Rockstroh JK, Bhagani S, Benhamou Y, Bruno R, Mauss S, Peters M, et al.; EACS Executive Committee. European AIDS Clinical Society (EACS) guidelines for the clinical management and treatment of chronic hepatitis $\mathrm{B}$ and C co-infection in HIV-infected adults. HIV Med 2008;9:82-88.

86. Vispo E, Barreiro P, Pineda JA, Mira JA, Maida I, Martín-Carbonero L, et al. Low response to pegylated interferon plus ribavirin in HIV-infected patients with chronic hepatitis $\mathrm{C}$ treated with abacavir. Antivir Ther 2008;13(3):429-437

87. Laufer N, Laguno M, Perez I, Cifuentes C, Murillas J, Vidal F, et al. Abacavir does not influence the rate of virological response in HIV-HCVcoinfected patients treated with pegylated interferon and weight-adjusted ribavirin. Antivir Ther 2008;13(7):953-957.

88. Mira JA, López-Cortés LF, Barreiro P, Tural C, Torres-Tortosa M, de Los Santos Gil I, et al. Efficacy of pegylated interferon plus ribavirin treatment in HIV/hepatitis $\mathrm{C}$ virus co-infected patients receiving abacavir plus lamivudine or tenofovir plus either lamivudine or emtricitabine as nucleoside analogue backbone. J Antimicrob Chemother 2008;62(6):1365-1373.

89. Van den Eynde E, Quer J, Cubero M, Curran A, Homs M, Falcó V, et al. Abacavir co-administration does not interfere with the suppressive activity of ribavirin in an HCV replicon system [abstract 963]. 18th Conference on Retroviruses and Opportunistic Infections; 2011 Feb 27 - Mar 2; Boston (MA).

90. Morello J, Soriano V, Barreiro P, Medrano J, Madejo A, Gonzalez-Pardo G, et al. Plasma ribavirin trough concentrations at week 4 predict hepatitis $C$ virus $(\mathrm{HCV})$ relapse in $\mathrm{HIV}-\mathrm{HCV}$-coinfected patients treated for chronic hepatitis C. Antimicrob Agents Chemother 2010;54(4):1647-1649.

91. Seden K, Back D, Khoo S. New directly acting antivirals for hepatitis C: potential for interaction with antiretrovirals. I Antimicrob Chemother 2010;65(6):1079-1085.

92. Incivek (telaprevir) product monograph. Cambridge (MA): Vertex Pharmaceuticals Inc; 2011

93. Hulskotte EGJ, Feng HP, Xuan F, van Zutven N, O’Mara E, Wagner J, et al. Pharmacokinetic interaction between the HCV protease inhibitor boceprevir and ritonavir-boosted HIV-1 protease inhibitors atazanavir, lopinavir, and darunavir [abstract 771LB]. 19th Conference on Retroviruses and Opportunistic Infections; 2012 Mar 5-8: Seattle (WA).

94. Victrelis (boceprevir) product monograph. Whitehouse Station (NJ): Schering Corporation; 2011.

95. Van Heeswijk RPG, Vandevoorde A, Boogaerts G, Vangeneugden T, De Paepe E, Polo R, et al. Pharmacokinetic interactions between ARV agents and the investigational $\mathrm{HCV}$ protease inhibitor TVR in healthy volunteers [abstract 119]. 18th Conference on Retroviruses and Opportunistic Infections; 2011 Feb 27 - Mar 2; Boston (MA)
96. de Kanter C, Blonk M, Colbers A, Fillekes Q, Schouwenberg B, Burger D. The influence of the HCV protease inhibitor bocepravir on the pharmacokinetics of the HIV integrase inhibitor raltegravir [abstract 772LB]. 19th Conference on Retroviruses and Opportunistic Infections; 2012 Mar 5-8; Seattle (WA).

97. Van Heeswijk RPG, Garg V, Boogaerts G, et al. The pharmacokinetic interaction between telaprevir and raltegravir in healthy volunteers [abstract A1-1738a]. 51st Interscience Conference on Antimicrobial Agents and Chemotherapy; 2011 Sep 17-20; Chicago (IL).

98. Antoniou T, Tseng A. Interactions between recreational drugs and antiretroviral agents. Ann Pharmacother 2002;36(10):1598-1613.

99. Krüsi A, Millroy MJ, Kerr T, Zhang R, Guillemi S, Hogg R, et al. Ongoing drug use and outcomes from highly active antiretroviral therapy among injection drug users in a Canadian setting. Antivir Ther 2010;15(5):789-96.

100. Morris JD, Golub ET, Mehta SH, Jacobson LP, Gange SJ. Injection drus use and patterns of highly active antiretroviral therapy use: an analysis of ALIVE, WIHS, and MACS cohorts. AIDS Res Ther 2007;4:12.

101. Wood E, Hogg RS, Kerr T, Palepu A, Zhang R, Montaner JS. Impact of accessing methadone on the time to initiating HIV treatment among antiretroviral-naive HIV-infected injection drug users. AIDS 2005;19(8):837-839.

102. Watkins CC, Pieper AA, Treisman GJ. Safety considerations in drug treatment of depression in HIV-positive patients. An updated review. Drug Saf 2011;34(8):623-639.

103. Nel A, Kagee A. Common mental health problems and antiretroviral therapy adherence. AIDS Care 2011;23(11):1360-1365.

104. Thompson MA, Mugavero MJ, Amico KR, Cargill VA, Chang LW, Gross R, et al. Guidelines for improving entry into and retention in care and antiretroviral adherence for persons with HIV: evidence-based recommendations from an International Association of Physicians in AIDS Care Panel. Ann Intern Med 2012 Mar 5. Epub ahead of print. Available from: www.annals.org/cgi/content/abstract/0003-4819-156-11-201206050$00419 \mathrm{v} 1$

105. Transformation through collective action: best practices in migration, HIV and mental health. Summary report. Toronto $(\mathrm{ON})$ : Committee for Accessible AIDS Treatment; 2008 [cited 2010 Sep 2]. Available from: www.hivimmigration.ca/Publications/Transformation $\% 20$ Summary\%20Report\%202008.pdf

106. Miller C, Spittal P, Wood E, Chan K, Schechter M, Montaner J, et al. Inadequacies in antiretroviral therapy use among Aboriginal and other Canadian populations. AIDS Care 2006;18(8):968-976.

107. Wood E, Kerr T, Palepu A, Zhang R, Strathdee S, Tyndall M, et al Slower uptake of HIV antiretroviral therapy among Aboriginal injection drug users. J Infect 2006;52(4):233-236.

108. Mehrabadi A, Craib KJ, Patterson K, Adam W, Moniruzzaman A, Ward-Burkitt B, et al. The Cedar Project: a comparison of HIV-related vulnerabilities amongst young Aboriginal women surviving drug use and sex work in two Canadian cities. Int J Drug Policy 2008;19(2):159-168.

109. Hughes C, Zuk D, Foisy M, Robinson J, Singh AE, Houston S. Prenatal screening and perinatal HIV transmission in Northern Alberta, 1999-2006. Am J Public Health 2009;99 Suppl 2:S412-S416.

110. Bangsberg DR, Perry S, Charlebois ED, Clark RA, Robertson M, Zolopa $\mathrm{AR}$, et al. Non-adherence to highly active antiretroviral therapy predicts progression to AIDS. AIDS 2001;15(9):1181-1183.

111. Wood E, Hogg RS, Yip B, Harrigan PR, O'Shaughnessy MV, Montaner JS. Effect of medication adherence on survival of HIV-infected adults who start highly active antiretroviral therapy when the CD4+ cell count is 0.200 to $0.350 \times 10(9)$ cells/L. Ann Intern Med 2003;139(10):810-816.

112. Lima VD, Harrigan R, Bangsberg DR, Hogg RS, Gross R, Yip B, et al. The combined effect of modern highly active antiretroviral therapy regimens and adherence on mortality over time. J Acquir Immune Defic Syndr 2009;50(5):529-536.

113. Paterson DL, Swindells S, Mohr J, Brester M, Vergis EN, Squier C, et al. Adherence to protease inhibitor therapy and outcomes in patients with HIV infection. Ann Intern Med 2000;133(1):21-30

114. Bangsberg DR. Less than 95\% adherence to nonnucleoside reversetranscriptase inhibitor therapy can lead to viral suppression. Clin Infect Dis 2006;43(7):939-941.

115. Raffa JD, Tossonian HK, Grebely J, Petkau AJ, DeVlaming S, Conway B. Intermediate highly active antiretroviral therapy adherence thresholds and empirical models for the development of drug resistance mutations. $J$ Acquir Immune Defic Syndr 2008;47(3):397-399.

116. Bangsberg DR, Ragland K, Monk A, Deeks SG. A single tablet regimen is associated with higher adherence and viral suppression than multiple tablet regimens in HIV+ homeless and marginally housed people. AIDS 2010;24(18):2835-2840. 
117. Cohen C, Davis KL, Meyers J. Association between daily antiretroviral pill burden and hospitalization risk in a Medicaid population with HIV [abstract H2-791]. 51st Interscience Conference on Antimicrobial Agents and Chemotherapy; 2011 Sep 17-20; Chicago (IL).

118. Gardner EM, Burman WJ, Maravi ME, Davidson AJ. Durability of adherence to antiretroviral therapy on initial and subsequent regimens. AIDS Patient Care STDs 2006;20(9):628-636.

119. Atkinson MJ, Petrozzino JJ. An evidence-based review of treatment-related determinants of patients' nonadherence to HIV medications. AIDS Patient Care STDs 2009;23(11):903-914.

120. Acri TL, Grossberg RM, Gross R. How long is the right interval for assessing antiretroviral pharmacy refill adherence? J Acquir Immune Defic Syndr 2010;54(5):e16-e19.

121. Arnsten JH, Demas PA, Farzedegan H, Grant RW, Gourevitch MN, Chang CJ, et al. Antiretroviral therapy adherence and viral suppression in HIV-infected drug users: comparison of self-report and electronic monitoring. Clin Infect Dis 2001;33(8):1417-1423.

122. Simoni JM, Amico KR, Smith L, Nelson K. Antiretroviral adherence interventions: translating research findings to the real world clinic. Curr HIVIAIDS Rep 2010;7(1):44-51.

123. Simoni JM, Kurth AE, Pearson CR, Pantalone DW, Merrill JO, Frick PA Self-report measures of antiretroviral therapy adherence: a review with recommendations for HIV research and clinical management. AIDS Behav 2006;10(3):227-245.

124. Elzi L, Marzolini C, Furrer H, Ledergerber B, Cavassini M, Hirschel B, et al.; Swiss HIV Cohort Study. Treatment modification in human immunodeficiency virus-infected individuals starting combination antiretroviral therapy between 2005 and 2008. Arch Intern Med 2010;170(1):57-65.

125. Edwards IR, Aronson JK. Adverse drug reactions: definitions, diagnosis, and management. Lancet 2000;356(9237):1255-1259.

126. Schiller DS. Identification, management, and prevention of adverse effects associated with highly active antiretroviral therapy. Am J Health Syst Pharm 2004;61(23):2507-2522.

127. Vidal F, Gutiérrez F, Gutiérrez M, Olona M, Sánchez V, Mateo G, et al. Pharmacogenetics of adverse effects due to antiretroviral drugs. AIDS Rev 2010;12(1):15-30.

128. Mallal S, Phillips E, Carosi G, Molina JM, Workman C, Tomazic J, et al.; PREDICT-1 Study Team. HLA-B*5701 screening for hypersensitivity to abacavir. $N$ Engl J Med 2008;358(6):568-579.

129. Haas DW, Bartlett JA, Andersen JW, Sanne I, Wilkinson GR, Hinkle J, et al. Pharmacogenetics of nevirapine-associated hepatotoxicity: an Adult AIDS Clinical Trials Group Collaboration. Clin Infect Dis 2006;43(6): 783-786.

130. Gatanaga H, Hayashida T, Tsuchiya K, Yoshino M, Kuwahara T, Tsukdada $\mathrm{H}$, et al. Successful efavirenz dose reduction in HIV type 1 -infected individuals with cytochrome $\mathrm{P} 4502 \mathrm{~B} 6{ }^{*} 6$ and ${ }^{*} 26$. Clin Infect Dis 2007;45(9):1230-1237.

131. Rodriguez-Novoa S, Labarga P, Soriano V. Pharmacogenetics of tenofovir treatment. Pharmacogenomics 2009;10(10):1675-1685.

132. Lundgren JD, Battegay M, Behrens G, De Wit S, Guaraldi G, Katlama C, et al. European AIDS Clinical Society (EACS) guidelines on the prevention and management of metabolic diseases in HIV. HIV Med 2008;9(2):72-81.

133. Back DJ, Gibbons S, Khoo S. An update on therapeutic drug monitoring for antiretroviral drugs. Ther Drug Monitor 2006;28(3):468-473.

134. La Porte CJL, Back DJ, Blaschke T, Boucher CAB, Fletcher CV, Flexner C, et al. Updated guidelines to perform therapeutic drug monitoring for antiretroviral agents. Rev Antiviral Ther 2006;3:4-14.

135. Kredo T, Van der Walt JS, Siegfried N, Cohen K. Therapeutic drug monitoring of antiretrovirals for people with HIV. Cochrane Database Syst Rev 2009;(3):CD007268.

136. Liu X, Ma Q, Zhang F. Therapeutic drug monitoring in highly active antiretroviral therapy. Expert Opin Drug Saf 2010;9(5):743-758.

137. Burger D, Hugen P, Reiss P, Gyssens I, Schneider M, Kroon F, et al.; ATHENA Cohort Study Group. Therapeutic drug monitoring of nelfinavir and indinavir in treatment-naive HIV-1-infected individuals. AIDS 2003;17(8):1157-1165.

138. Fletcher CV, Anderson PL, Kakuda TN, Schacker TW, Henry K, Gross $\mathrm{CR}$, et al. Concentration-controlled compared with conventional antiretroviral therapy for HIV infection. AIDS 2002;16(4):551-560.

139. Khoo SH, Lloyd J, Dalton M, Bonington A, Hart E, Gibbons S, et al. Pharmacologic optimization of protease inhibitors and nonnucleoside reverse transcriptase inhibitors (POPIN) — a randomized controlled trial of therapeutic drug monitoring and adherence support. J Acquir Immune Defic Syndr 2006;41(4):461-467.

140. Clevenbergh P, Garraffo R, Durant J, Dellamonica P. PharmAdapt: a randomized prospective study to evaluate the benefit of therapeutic monitoring of protease inhibitors: 12 week results. AIDS 2002;16(17):2311-2315.

141. Bossi P, Peytavin G, Ait-Mohand H, Delaugerre C, Ktorza N, Paris L, et al.
GENOPHAR: a randomized study of plasma drug measurements in association with genotypic resistance testing and expert advice to optimize therapy in patients failing antiretroviral therapy. HIV Med 2004;5(5): 352-359.

142. Torti C, Quiros-Roldan E, Regazzi M, De Luca A, Mazzotta F, Antinori A et al. A randomized controlled trial to evaluate antiretroviral salvage therapy guided by rules-based or phenotype-driven HIV-1 genotypic drug-resistance interpretation with or without concentration-controlled intervention: the Resistance and Dosage Adapted Regimens (RADAR) study. Clin Infect Dis 2005;40(12):1828-1836.

143. Brüggemann RJM, van Luin M, Colbers EPH, van den Dungen MW, Pharo C, Schouwenberg BJJW, et al. Effect of posaconazole on the pharmacokinetics of fosamprenavir and vice versa in healthy volunteers. $J$ Antimicrob Chemother 2010;65(10):2188-2194.

144. Higgins N, Tseng A, Sheehan NL, la Porte CJL. Antiretroviral therapeutic drug monitoring in Canada: current status and recommendations for clinical practice. Can J Hosp Pharm 2009;62(6):500-509.

145. Tam V, Knowles S, Cornish P, Fine N, Marchesano R, Etchells E Frequency, type and clinical importance of medication history errors at admission to hospital: a systematic review. CMAJ 2005;173(5):510-515.

146. Wong J, Bajcar J, Wong G, Alibhai S, Huh J, Cesta A, et al. Medication reconciliation at hospital discharge: evaluating discrepancies. Ann Pharmacother 2008;42(10):1373-1379.

147. Rastegar DA, Knight AM, Monolakis JS. Antiretroviral medication errors among hospitalized patients with HIV infection. Clin Infec Dis 2006, 43(7):933-938

148. Pastakia SD, Corbett AH, Raasch RH, Napravnik S, Correll TA. Frequency of HIV-related medication errors and associated risk factors in hospitalized patients. Ann Pharmacother 2008;42(4):491-497.

149. Corrigan M, Atkinson K, Sha B, Crank C. Evaluation of pharmacyimplemented medication reconciliation directed at antiretroviral therapy in hospitalized HIV/AIDS patients. Ann Pharmacother 2010;44(1):222-223.

150. DeLorenze GN, Follansbee SF, Nguyen DP, Klein DB, Horberg M, Quesenberry CP Jr, et al. Medication error in the care of HIV/AIDS patients: electronic surveillance, confirmation, and adverse events. Med Care 2005;43(9 Suppl):III63-III68.

151. Hellinger F, Encinosa W. The cost and incidence of prescribing errors among privately insured HIV patients. Pharmacoeconomics 2010;28(1):23-34.

152. Willig J, Westfall A, Allison J, Van Wagoner N, Chang P, Raper J, et al. Nucleoside reverse-transcriptase inhibitor dosing errors in an outpatient HIV clinic in the electronic medical record era. Clin Infect Dis 2007;45(5):658-661

153. Arnsten JH, Li X, Mizuno Y, Knowlton A, Gourevitch M, Handley K, et al. Factors associated with antiretroviral therapy adherence and medication errors among HIV-infected injection drug users. J Acquir Immune Defic Syndr 2007;46 Suppl 2:S64-S71.

154. Gray J, Hicks RW, Hutchings C. Antiretroviral medication errors in a national medication error database. AIDS Patient Care STDs 2005 19(12):803-812.

155. Medication reconciliation review. Cambridge (MA): Institute for Healthcare Improvement; 2004 [cited 2012 Mar 21]. Available from: www.communitycarenc.org/elements/media/files/ medicationreconciliationreview_luthermidelfort.pdf

156. Medication reconciliation: statement on the role of the pharmacist (2009). Ottawa (ON): Canadian Society of Hospital Pharmacists; 2009 [cited 2012 Mar 21]. Available from: www.cshp.ca/dms/dmsView/1_S_Med_ Rec_2009.pdf

157. Segarra-Newnham M. Preventing medication errors with a "Pharmacy Admission Note" for HIV-positive patients. Hosp Pharm 2002;37(1):34-37.

158. Carcelero E, Tuset M, Martin M, De Lazzari E, Codina C, Miró J, et al Evaluation of antiretroviral-related errors and interventions by the clinica pharmacist in hospitalized HIV-infected patients. HIV Med 2011; 12(8):494-499.

159. Arshad S, Rothberg M, Rastegar D, Spooner LM, Skiest D. Survey of physician knowledge regarding antiretroviral medications in hospitalized HIV-infected patients. I Int AIDS Soc 2009;12:1.

160. Mok S, Minson Q. Drug-related problems in hospitalized patients with HIV infection. Am J Health Syst Pharm 2008;65(1):55-59.

161. Vira T, Colquhoun M, Etchells E. Reconcilable differences: correcting medication errors at hospital admission and discharge. Qual Saf Health Care 2006;15(2):122-126.

162. Karapinar-Carkit F, Borgsteede S, Zoer J, Smit H, Egberts A, van den Bemt P. Effect of medication reconciliation with and without patient counseling on the number of pharmaceutical interventions among patients discharged from the hospital. Ann Pharmacother 2009;43(6):1001-1010.

163. Nickerson A, MacKinnon NJ, Roberts N, Saulnier L. Drug-therapy problems, inconsistencies and omissions identified during a medication reconciliation and seamless care service. Healthc Q 2005;8 Spec No:65-72. 
164. Seamless care: statement (2004). Ottawa (ON): Canadian Society of Hospital Pharmacists; 2004.

165. Foisy MM, Yakiwchuk EMK, Chiu I, Singh AE. Adrenal suppression and Cushing's syndrome secondary to an interaction between ritonavir and fluticasone: a review of the literature. HIV Med 2008;9(6):389-396.

166. Foisy MM, Tseng A, Blaikie N. Pharmacists' provision of continuity of care to patients with human immunodeficiency virus infection. Am J Health Syst Pharm 1996;53(9):1013-1017.

167. Ray W, Griffin M, Avorn J. Evaluating drugs after their approval for clinical use. N Engl J Med 1993;329(27):2029-2032.

168. Post-market surveillance of prescription drugs: using the evidence. Ottawa (ON): Canadian Institutes of Health Research; 2008.

169. The Sentinel Initiative: national strategy for monitoring medical product safety. Department of Health and Human Services, US Food and Drug Administration, Office of Critical Path Programs; 2008 [cited 2010 Apr 10]. Available from: www.fda.gov/downloads/Safety/FDAsSentinel Initiative/UCM124701.pdf

170. Kelman C, Pearson S, Day R, Holman C, Kliewer E, Henry D. Evaluating medicines: let's use all the evidence. Med J Aust 2007;186(5):249-252.

171. American College of Clinical Pharmacy Research Affairs Committee, Fagan SC, Touchette D, Smith JA, Sowinski KM, Dolovich L, Olson $\mathrm{KL}$, et al. The state of science and research in clinical pharmacy. Pharmacotherapy 2006;26(7):1027-1040.

172. Tseng A, Foisy M, Courchesne M, on behalf of the Canadian HIV/AIDS Pharmacists Network. Development of a national HIV/AIDS pharmacists network in Canada [abstract E11553]. 14th International AIDS Conference; 2002 Jul 7-12; Barcelona (Spain).

173. Fox P. "HIV Pharmacist ${ }^{\mathrm{TM}}$ " (AAHIVP) certification now available. $H I V$ Spec 2011;3(2):3. Available from: www.aahivm.org/Upload_Module/ upload/Provider\%20Resources/HIVSpecialistMagazineSpring2011.pdf
Shanna Chan, BScPharm, ACPR, AAHIVE, is with the Health Sciences Centre and Nine Circles Community Health Centre, Manitoba HIV Program, Winnipeg, Manitoba.

Natalie Dayneka, BScPhm, PharmD, FCSHP, is with the Pharmacy Department, Children's Hospital of Eastern Ontario, Ottawa, Ontario.

Pierre Giguère, BPharm, MSc(Pharm), MSc(Epi), is with the Immunodeficiency Clinic, The Ottawa Hospital, General Campus, Ottawa, Ontario.

Niamh Higgins, PharmD, AAHIVE, is with the Pharmacy Department, McGill University Health Centre, Montréal, Quebec.

Cara Hills-Nieminen, BSc(Pharm), is with the Ambulatory Pharmacy, St Paul's Hospital, Vancouver, British Columbia.

Jeff Kapler, BSCPharm, is with the Sheldon M Chumir Health Centre, Southern Alberta Clinic for HIV/AIDS, Calgary, Alberta.

Charles J L la Porte, PharmD, PhD, is with the University of Ottawa, The Ottawa Hospital, and the Ottawa Hospital Research Institute, Ottawa, Ontario.

Pam Nickel, BScPharm, is with the Northern Alberta HIV Program, Alberta Health Services, Edmonton, Alberta.

Laura Park-Wyllie, BScPhm, PharmD, MSc, is with St Michael's Hospital, the Institute for Clinical Evaluative Sciences, and the Li Ka Shing Knowledge Institute, Toronto, Ontario.

Carlo Quaia, BSc(Pharm), ACPR, is with the Oak Tree Clinic (HIV), Children's and Women's Health Centre of British Columbia, Vancouver, British Columbia.

Linda Robinson, BSCPhm, AAHIVE, is with the Pharmacy Department, Windsor Regional Hospital, Windsor, Ontario.

Nancy Sheehan, BPharm, MSc, is with the Faculty of Pharmacy, Université de Montréal, Montréal, Quebec.

Shannon Stone, BSP, is with the Positive Living Program, Royal University Hospital, Saskatoon, Saskatchewan.

Linda Sulz, BSP, PharmD, is with the Pasqua Hospital, Regina Health District, Regina, Saskatchewan.

Deborah Yoong, BScPhm, PharmD, is with the Pharmacy Department, St Michael's Hospital, Toronto, Ontario.

\section{Address correspondence to:}

Dr Alice Tseng

Immunodeficiency Clinic

Toronto General Hospital

585 University Avenue, 13N-1314

Toronto ON M5G 2N2

e-mail: alice.tseng@uhn.ca 


\section{Appendix 1. Strategies for Improving Patient Adherence}

1. For patients initiating new antiretroviral therapy, conduct an assessment:

- Identify the patient's needs, lifestyle, and social situation, including daily routine, employment, confidentiality issues, beliefs, and access to storage and refrigeration, as these factors may affect the choice of drug therapy.

- Determine the patient's knowledge of his or her disease and his or her expectations of treatment.

- Determine the patient's preferences regarding medications, including pill size, acceptable pill burden, and desirability of liquid formulations.

- Ensure that the patient has the financial means to pay for combination antiretrovial therapy. If the patient is accessing insurance benefits, ensure that prescription copayments are affordable and that any prior or special authorization approvals are obtained for all medications in the regimen.

- Determine whether the assistance of other health care professionals is required, and refer if necessary.

2. Create an environment that ensures privacy, and discuss any confidentiality concerns the patient may have (e.g., misgivings about sharing health information with insurance providers and employers, because of the risk of potential disclosure of HIV status).

3. Use fixed-dose combination medications where possible, to reduce the pill burden, and aim to use once- or twice-daily medication regimens where possible.

4. Individualize medication schedules to accommodate the patient's lifestyle (including temporary adjustments for patients travelling through different time zones). Consider web-based software programs such as MedActionPlan (www.medactionplan.com/) to create printable and shareable medication calendars.

5. Educate the patient about optimal medication use, including dietary restrictions, procedures for missed doses, and drug interactions.
Balance any discussion of adverse effects with emphasis on the benefits of antiretroviral therapy, provide tips on how to manage adverse reactions, and tell the patient whom to contact if such reactions occur. Supplement the discussion with personalized written information when possible (see Table 1 for a list of websites that offer patient fact sheets).

6. Encourage use of dosettes or other tools designed to accommodate the complex medication regimens of HIV patients.

7. Encourage the use of reminder devices. Programmable alarms on cell phones and watches are convenient and unobtrusive. Dose reminder programs that rely on texting have been shown to promote adherence.

8. Ensure timely acquisition of medications for patients, and maintain a consistent stock of antiretrovirals in the pharmacy. When a patient is beginning a new combination regimen, suggest dispensing the drugs in 1-month allotments to allow for timely interaction with the health care team and to ensure that the patient is able to tolerate the new regimen.

9. Encourage patients to consolidate all of their prescriptions at one pharmacy. When possible, try to link the dispensing of antiretroviral agents with dispensing of other long-term medications (e.g. methadone or tuberculosis medications dispensed through directly observed therapy programs) to facilitate adherence and monitoring.

10. Minimize medication costs by becoming familiar with government and third-party payment plans in your province or state.

11.Implement a follow-up system to monitor patient adherence, and provide support (e.g., pharmacist-initiated telephone call-back system).

12. Use a neutral tone when asking about adherence, using open-ended questions to encourage the patient to discuss challenges and difficulties in taking medications as prescribed.

\begin{tabular}{lll}
\multicolumn{3}{c}{ Advertisers } \\
\hline & Ad Page & Prescribing Information \\
\hline Hospira / Docetaxel & 90 & - \\
\hline Hospira / Corporate & 93 & - \\
\hline Otsuka / Samaca & 88,89 & 155,156 \\
\hline Pfizer / Injectables & 94 & - \\
\hline Pharmaceutical Partners of Canada / Corporate & IFC & 153,154 \\
\hline Pharmaceutical Partners of Canada / Corporate & OBC & - \\
\hline Sandoz / Corporate & 86 & - \\
\hline Sandoz / Corporate & 97 & - \\
\hline
\end{tabular}

